\title{
Transmission characteristics of heterozygous cases of Creutzfeldt-Jakob disease with variable abnormal prion protein allotypes
}

\author{
Anne Ward ${ }^{1}$, Jason R. Hollister ${ }^{1}$, Kristin McNally ${ }^{2}$, Diane L. Ritchie ${ }^{3}$, Gianluigi Zanusso ${ }^{4}$ and Suzette A. Priola ${ }^{1 *}$ (D)
}

\begin{abstract}
In the human prion disease Creutzfeldt-Jakob disease (CJD), different CJD neuropathological subtypes are defined by the presence in normal prion protein ( $\mathrm{PrP}^{\mathrm{C}}$ ) of a methionine or valine at residue 129, by the molecular mass of the infectious prion protein $\mathrm{PrP}^{\mathrm{Sc}}$, by the pattern of $\mathrm{PrP}^{\mathrm{Sc}}$ deposition, and by the distribution of spongiform change in the brain. Heterozygous cases of CJD potentially add another layer of complexity to defining CJD subtypes since $\mathrm{PrP}^{\mathrm{SC}}$ can have either a methionine (PrPSC-M129) or valine (PrP $\left.{ }^{\mathrm{SC}}-\mathrm{V} 129\right)$ at residue 129. We have recently demonstrated that the relative amount of $\mathrm{PrP}^{\mathrm{SC}}-\mathrm{M} 129$ versus $\mathrm{PrP}^{\mathrm{SC}}-\mathrm{V} 129$, i.e. the $\mathrm{PrP}^{\mathrm{SC}}$ allotype ratio, varies between heterozygous CJD cases. In order to determine if differences in PrP ${ }^{S c}$ allotype correlated with different disease phenotypes, we have inoculated 10 cases of heterozygous CJD (7 sporadic and 3 iatrogenic) into two transgenic mouse lines overexpressing $\mathrm{PrP}^{C}$ with a methionine at codon 129. In one case, brain-region specific differences in $\mathrm{PrP}^{\mathrm{Sc}}$ allotype appeared to correlate with differences in prion disease transmission and phenotype. In the other 9 cases inoculated, the presence of $\mathrm{PrP}^{\mathrm{Sc}}$-V129 was associated with plaque formation but differences in PrPSc allotype did not consistently correlate with disease incubation time or neuropathology. Thus, while the $\operatorname{PrP}^{\mathrm{Sc}}$ allotype ratio may contribute to diverse prion phenotypes within a single brain, it does not appear to be a primary determinative factor of disease phenotype.
\end{abstract}

Keywords: Prion, Creutzfeldt-Jakob disease, CJD, PrPSc allotype

\section{Introduction}

Prion diseases are fatal, transmissible neurodegenerative diseases of mammals that are associated with the misfolding of a normally protease-sensitive and soluble protein called prion protein or $\operatorname{PrP}^{\mathrm{C}}$, into a partially protease-resistant, insoluble and infectious form termed $\mathrm{PrP}^{\mathrm{Sc}}$ [18]. Accumulation of $\mathrm{PrP}^{\mathrm{Sc}}$ in the brain over time, as large amyloid or non-amyloid aggregates, eventually

\footnotetext{
* Correspondence: spriola@nih.gov

${ }^{1}$ Rocky Mountain Laboratories, Laboratory of Persistent Viral Diseases, National Institute of Allergy \& Infectious Diseases, National Institutes of Health, 903 S. 4th Str, Hamilton, MT 59840, USA

Full list of author information is available at the end of the article
}

leads to clinical prion disease and death. In humans, prion diseases can be hereditary, sporadic, or acquired. In hereditary prion diseases, mutations in the prion protein $(P R N P)$ gene are associated with different types of prion disease such as Gerstmann-Sträussler-Scheinker syndrome, fatal familial insomnia, and genetic Creutzfeldt-Jakob disease [26]. Sporadic CreutzfeldtJakob disease (sCJD), which is thought to arise as the result of spontaneous misfolding of $\operatorname{PrP}^{\mathrm{C}}$ in the brain into infectious $\mathrm{PrP}^{\mathrm{Sc}}$, is the most common form of human prion disease and occurs at an incidence of approximately1-2 cases per million people worldwide. Acquired forms of prion disease can result from the ingestion of 
prion contaminated tissue, as was the case with variant CJD which has been linked to ingestion of bovine spongiform encephalopathy (BSE) contaminated products, and kuru, which was the result of the cannibalistic practices of the Fore tribe in New Guinea. They can also result from exposure to prion contaminated medical instruments, devices or products such as dura mater grafts, pituitary gland derived human growth hormone, and human blood and blood products. Collectively, these latter forms of acquired prion disease are known as iatrogenic CJD (iCJD) [22].

In humans, there is a naturally occurring polymorphism in PRNP represented by either a methionine or valine at codon 129 which helps to define the neuropathological subtype of sCJD [25, 30, 31]. CJD subtypes are also classified according to the size of $\mathrm{PrP}^{\mathrm{Sc}}$ following protease digestion [30-32, 41]. Type 1 CJD is associated with a $\operatorname{PrP}^{\mathrm{Sc}}$ molecule of $21 \mathrm{kDa}$ while Type $2 \mathrm{CJD}$ is associated with a $19 \mathrm{kDa} \operatorname{PrP}^{\mathrm{Sc}}$ molecule [30, 31]. There are therefore 6 potential subtypes of SCJD based on the possible combinations of $\operatorname{PrP}^{\mathrm{Sc}}$ size and PRNP genotype: MM1, MM2, VV1, VV2, MV1, and MV2. CJD subtype can be further defined by different patterns of pathology (i.e. spongiform change and neuronal loss) and $\operatorname{PrP}^{\mathrm{Sc}}$ deposition in the brain $[3,30,31,33]$, and by transmission properties into non-human primates [8] or transgenic mice expressing human $\operatorname{PrP}^{C}[1,2,5,9,13$, $23,44]$. Based on all of these criteria, there are currently believed to be 6 major subtypes or strains of sCJD (in order of frequency): MM1/MV1, VV2, MV2K (i.e. Type $2 \operatorname{PrP}^{\mathrm{Sc}}$ with the " $\mathrm{K}$ " designating kuru-type plaques), MM2T (thalamic), MM2C (cortical), and VV1 [3].

Within CJD subtypes, there can be atypical disease presentations as well as variation in neuropathological phenotypes [3, 33, 34]. The molecular mechanisms underlying this variability are unclear but may be explained by the fact that multiple $\operatorname{PrP}^{\mathrm{Sc}}$ types can cooccur within different CJD subtypes [10, 19, 24, 31, 34, $36,41]$. Approximately one-third of SCJD cases show the co-presence of Type 1 and Type $2 \operatorname{PrP}^{\mathrm{Sc}}$ within the same, or different, regions of a single brain [10, 34, 36]. For example, the most common mixed CJD type, MV1 + $2 \mathrm{C}$, refers to cases with Type $1 \mathrm{PrP}^{\mathrm{Sc}}$ that also have cortical pathology (designated by the $\mathrm{C}$ ) and focal Type 2 $\mathrm{PrP}^{\mathrm{Sc}}$ deposition [33]. Thus, within a single subtype of sCJD, prions with different conformations may be present that could influence disease progression and pathogenesis in unpredictable ways.

The prion protein allotype may also be influencing disease phenotype. It is known that heterozygosity in $\operatorname{PrP}^{\mathrm{C}}$ at codon 129 is associated with resistance to $\mathrm{SCJD}$, as well as later disease onset and longer disease duration in kuru [11]. In SCJD, a valine at residue 129 has been associated with plaque formation and a longer clinical disease course [21] while a methionine at residue 129 has been associated with a more synaptic pattern of $\operatorname{Pr} \mathrm{P}^{\mathrm{Sc}}$ deposition and a shorter clinical course [21]. Thus, in heterozygous cases of sCJD where both $\operatorname{PrP}^{\mathrm{Sc}}$ with a methionine $\left(\mathrm{PrP}^{\mathrm{Sc}}-\mathrm{M} 129\right)$ and $\operatorname{PrP}^{\mathrm{Sc}}$ with a valine $\left(\mathrm{PrP}^{\mathrm{Sc}}-\mathrm{V} 129\right)$ may be present, the relative amounts of each allotype (i.e. the $\mathrm{PrP}^{\mathrm{Sc}}$ allotype ratio), might influence disease pathogenesis. Indeed, there is considerable phenotypic variation within heterozygous cases of MV2 sCJD $[3,23]$ which might be explained if the $\operatorname{PrP}^{\mathrm{Sc}}$ allotype ratio influenced disease parameters such as disease incubation time and neuropathology.

Transmission of MV heterozygous cases of CJD into transgenic mice expressing human $\operatorname{PrP}^{\mathrm{C}}$ would help to further elucidate the role of $\operatorname{PrP}^{\mathrm{Sc}}$ allotype on disease phenotype. Unfortunately, only a few such studies have been published $[1,2,5,20,23,25,44]$ and most involved the inoculation of only one or two cases of heterozygous sCJD [1, 2, 5, 20, 23]. In one study, inoculation of MV CJD into transgenic mice expressing human $\operatorname{PrP}^{\mathrm{C}}$-M129 resulted in either short or long incubation times, leading the authors to hypothesize that incubation time might reflect differences in the propagation of $\mathrm{PrP}^{\mathrm{Sc}}$-M129 versus $\mathrm{PrP}^{\mathrm{Sc}}-\mathrm{V} 129$ [2]. However, since it is only recently that mass spectrometry has been used to determine $\mathrm{PrP}^{\mathrm{Sc}}$ allotype in MV heterozygous cases of CJD [28], the $\mathrm{PrP}^{\mathrm{Sc}}$ allotype ratio of the MV heterozygous CJD cases transmitted into transgenic mice to date remains unknown. Thus, there is no direct evidence for what effect $\operatorname{PrP}^{\mathrm{Sc}}$ allotype may have on prion disease incubation time and phenotype.

We have recently shown that the $\operatorname{PrP}^{\mathrm{Sc}}$ allotype ratio is variable in MV1 and MV2 cases of sCJD but somewhat less variable in cases of MV2K iCJD in the United Kingdom (UK) [28] that were the result of exposure to prion contaminated human growth hormone derived from cadavers. In particular, our analysis of four MV2 sCJD cases showed that statistically significant differences in the amount of $\operatorname{PrP}^{\mathrm{Sc}}$ M129 isolated from different brain regions of a single patient were associated with brain region-specific differences in $\mathrm{PrP}^{\mathrm{Sc}}$ deposition [28]. In order to understand the potential contribution of the $\mathrm{PrP}^{\mathrm{Sc}}$ allotype to disease transmission and phenotype in heterozygous CJD subtypes, we inoculated 10 cases of MV heterozygous SCJD or iCJD into transgenic mice overexpressing human $\operatorname{PrP}^{\mathrm{C}}-\mathrm{M} 129$. In one case, brainregion specific differences in $\operatorname{PrP}^{\mathrm{Sc}}$ allotype appeared to correlate with differences in prion disease transmission and phenotype. Differences in $\operatorname{PrP}^{\mathrm{Sc}}$ allotype did not consistently correlate with disease incubation times in the other 9 cases but the presence of $\mathrm{PrP}^{\mathrm{Sc}}$ V129 was associated with plaque deposition. Thus, while our data are consistent with differences in the $\mathrm{PrP}^{\mathrm{Sc}}$ allotype contributing to variable phenotypes in 
MV heterozygous cases of CJD, it is not the primary determinant of the final disease phenotype.

\section{Materials and methods Ethics statement}

Human brain samples were obtained either from the National CJD Research \& Surveillance Unit Brain and Tissue Bank, which is part of the MRC Edinburgh Brain \& Tissue Bank (Edinburgh Brain Bank 16-ES-0084), UK, or from the University of Verona, Italy. These latter tissues were obtained at autopsy and sent to the Neuropathology Unit at the University of Verona for statutory definite diagnosis of CJD. Ethical approval for the acquisition and use of post-mortem human CJD brain samples was obtained from the National Institutes of Health (NIH) Office of Human Subject Research (Exempt \#11763 and \#12725) and no patient identifiable data was transferred to the NIH. The neuropathological and biochemical characteristics of all samples inoculated have been previously described [28].

\section{Inoculation of $\operatorname{tg} 66$ and $\operatorname{tgRM}$ mice}

The animal experimental protocol was reviewed and approved by the Rocky Mountain Laboratories Animal Care and Use Committee. This study was carried out in strict accordance with the recommendations in the Guide for the Care and Use of Laboratory Animals of the National Institutes of Health.

Tg66 and tgRM mice over-expressing human $\operatorname{PrP}^{\mathrm{C}}$ M129 [37] were infected by injecting $50 \mu$ of brain homogenate from confirmed CJD cases via the intracerebral route using a 27 -gauge $1 / 2$ inch needle. All brain homogenates were prepared using the following procedure. A $10 \%$ weight per volume (w/v) solution was prepared from frozen brain tissue in sterile phosphate buffered saline by homogenizing with $2 \times 30 \mathrm{~s}$ bursts using a Minibeadbeater (Biospec Products). Each sample was sonicated for 2 mins, then further diluted to $1 \% \mathrm{w} / \mathrm{v}$ in phosphate buffered balanced salts solution (PBBS; $1.5 \mathrm{mM}$ potassium phosphate monobasic, $6.6 \mathrm{mM}$ sodium phosphate dibasic anhydrous, $1.3 \mathrm{mM}$ calcium chloride anhydrous, $4.3 \mathrm{mM}$ potassium chloride, $123.2 \mathrm{mM}$ sodium chloride, $1 \mu \mathrm{M}$ magnesium chloride 6-hydrate, $0.8 \mu \mathrm{M}$ magnesium sulfate 7 - hydrate, $1 \%$ phenol red, and $5.6 \mathrm{mM}$ glucose) plus $2 \%$ fetal bovine serum. Samples were vortexed and then spun for $1 \mathrm{~min}$ at $3000 \mathrm{rpm}$ immediately prior to injection. The titer of the CJD MM1 control was $2 \times 10^{5.4} \mathrm{ID}_{50} / \mathrm{g}$ brain tissue.

Mice were monitored twice weekly for signs of disease. Once early clinical signs appeared, such as aberrant nesting and ruffled fur, mice were checked daily. Late neurological clinical signs included kyphosis, somnolence, reluctance or inability to move normally, ataxia, and visible weight loss. When mice displayed these late clinical signs, they were euthanized using isoflurane in a jar in a scavenger hood. Brains were removed, cut in half along the sagittal midline, and one half was frozen in liquid nitrogen for use in western blot while the other half was placed into $10 \%$ normal buffered formalin (NBF) for fixation prior to immunohistochemical analysis.

\section{Real time quaking induced conversion (RT-QulC) endpoint titration assay}

Brain homogenates were serially diluted (10-fold dilution series from $10^{-3}$ to $10^{-10}$ ) in RT-QuIC reaction solution ( $0.1 \%$ sodium dodecyl sulfate (SDS), $1 \times \mathrm{N}-2$ supplement (ThermoFisher) and $1 \mathrm{x}$ phosphate buffered saline PBS; $130 \mathrm{mM} \mathrm{NaCl}, 10 \mathrm{mM}$ PO4, pH 7.4). Prion seeding activity for each dilution was measured in a 96-well plate by adding $2 \mu \mathrm{L}$ diluted brain homogenate to $98 \mu \mathrm{L}$ RTQuIC reaction solution to give final concentrations of $0.1 \mathrm{mg} / \mathrm{ml}$ bacterially derived and purified recombinant hamster $\operatorname{PrP}^{\mathrm{C}}$ (amino acid residues 90-231) [29], $10 \mathrm{mM}$ phosphate buffer $\mathrm{pH}$ 7.4, $10 \mu \mathrm{M}$ thioflavin T (ThT), 300 $\mathrm{mM} \mathrm{NaCl}, 1 \mathrm{mM}$ ethylenediaminetetraacetic acid (EDTA) and $0.002 \%$ SDS. Four technical replicate reaction wells were prepared for each dilution. The plates were then shaken in a temperature-controlled fluorescence plate reader (BMG FLUOstar) at $50{ }^{\circ} \mathrm{C}$ with cycles of $1 \mathrm{~min}$ double orbital shaking at $700 \mathrm{rpm}$ and $1 \mathrm{~min}$ of rest. ThT fluorescence was measured at 45-min intervals. For each sample, the assay was repeated three times for a total of 12 replicate wells per dilution. The prion seeding dose (SD), defined as the dilution in an endpoint RT-QuIC dilution assay at which $50 \%$ of the wells are ThT positive [45], was calculated using the SpearmanKärber method [17] and reported as $\mathrm{SD}_{50} / \mathrm{g}$ of brain homogenate.

\section{Immunohistochemistry}

Formalin fixed tissue was processed and embedded in paraffin. Sections $(5 \mu \mathrm{m})$ were cut using a standard Leica microtome, placed on positively charged glass slides, and air-dried overnight at room temperature. Prior to deparaffinization slides were heated in an oven at $60^{\circ} \mathrm{C}$ for $20 \mathrm{~min}$. The brain tissue was deparaffinized in Pro-Par clearant (Anatech Innovator), followed by rehydration in decreasing concentrations of ethanol with a final rinse in distilled water. Slides were immersed in $10 \mathrm{mM}$ citrate buffer ( $\mathrm{pH} 6.0$ ), placed in a Biocare decloaking chamber, and treated at $120^{\circ} \mathrm{C}$ at $20 \mathrm{lb} . /$ in $^{2}$ pressure for $20 \mathrm{~min}$. After cooling, the slides were stained using DABMap kit and hematoxylin counterstain on an automated Discovery XT staining system (Ventana Medical Systems). The primary antibody was the anti-PrP mouse monoclonal antibody 3F4 conjugated to biotin (Covance) diluted 1:50 in Ventana antibody dilution buffer (Ventana Medical Systems) with an incubation time of $60 \mathrm{~min}$. 


\section{Other stains}

The presence of amyloid plaques was confirmed by staining deparaffinized sections with the amyloid dye Thioflavin S (ThioS) as previously described [35]. Hamotoxylin and eosin (H\&E) staining was performed by hand on deparaffinized slides using Shandon Instant Hemotoxylin and Eosin (Thermo Scientific) according to the manufacturer's instructions.

\section{SDS-PAGE and Western blotting}

Brain halves from tg66 and tgRM mice were homogenized in PBS to $20 \%(\mathrm{w} / \mathrm{v})$ with $2 \times 30 \mathrm{~s}$ bursts using a Minibeadbeater. Tris-HCL (pH 8.5), sodium deoxycholate, and Triton X-100 were added to the homogenate to give final concentrations of $0.1 \mathrm{M}, 1 \%$, and $1 \%$, respectively. Samples were protease treated by adding proteinase $\mathrm{K}(\mathrm{PK})$ to a final concentration of $63.3 \mu \mathrm{g} / \mathrm{ml}$ followed by incubation for $30 \mathrm{~min}$ at $37^{\circ} \mathrm{C}$ in a circulating water bath. The PK was then neutralized by adding $0.1 \mathrm{M}$ phenylmethylsulfonyl fluoride (PMSF) to a final concentration of $0.01 \mathrm{M}$. For each sample, $17.2 \mu \mathrm{l}$ of Novex NuPage lithium dodecyl sulfate (LDS) 4X sample loading buffer (Life Technologies) was pre-diluted to 2X, $17.2 \mu \mathrm{l}$ of sample was added, and the sample boiled for $3 \mathrm{~min}$. Samples were loaded onto a 15 well, $1.5 \mathrm{~mm}$ NuPage 4-20\% Bis-Tris gradient gel (Invitrogen) and run for $75 \mathrm{~min}$ at constant voltage $(120 \mathrm{~V})$.

After electrophoresis, samples were transferred to polyvinylidene difluoride (PVDF) membrane (Millipore) at $37 \mathrm{~V}$ overnight at $4^{\circ} \mathrm{C}$ in Towbin's buffer $(0.25 \mathrm{M}$ Tris, $1.92 \mathrm{M}$ Glycine, $0.01 \%$ SDS, $20 \%$ methanol). Membranes were blocked with Blotto (5\% milk in Tris buffered saline plus Tween (TBST): $137 \mathrm{mM} \mathrm{NaCl}, 2.7 \mathrm{mM}$ $\mathrm{KCl}, 19 \mathrm{mM}$ Tris base, $0.1 \%$ Tween 20 ) for $1.5 \mathrm{~h}$. The membrane was developed using the anti-PrP mouse monoclonal antibody 3F4 conjugated to biotin (Covance) at a 1:10,000 dilution for $1.5 \mathrm{~h}$ at room temperature on a shaking platform. Following a $30 \mathrm{~min}$ period of 3 to 4 washes in TBST, the membrane was incubated for $1 \mathrm{~h}$ at room temperature in a 1:250,000 dilution in TBST of streptavidin-horseradish peroxidase (SA-HRP, Cell Signaling Technology). The wash step above was repeated and the membranes rinsed in distilled water before being developed with SuperSignal West Femto Maximum Sensitivity Substrate (Thermo Scientific) for detection on X-ray film.

\section{Statistics}

The unpaired student's t-text, Tukey's multiple comparisons test, linear regression, and sample mean and standard deviation were all calculated using the GraphPad Prism software package (version 8.2).

\section{Results}

Transmission of MV heterozygous cases of SCJD and iCJD into transgenic mice overexpressing human $\operatorname{PrP}^{\mathrm{C}}$

We have previously shown that variability in the $\operatorname{PrP}^{\mathrm{Sc}}$ allotype ratio can be associated with different types of $\mathrm{PrP}^{\mathrm{Sc}}$ deposition within the brain [28]. In order to determine whether or not the $\mathrm{PrP}^{\mathrm{Sc}}$ allotype ratio influenced the transmission properties of MV heterozygous cases of CJD, brain samples from 10 cases of codon 129 heterozygous sCJD $(n=7)$ or iCJD $(n=3)$ whose prion disease phenotype had been previously characterized both neuropathologically and biochemically [28], were tested for their ability to transmit disease to transgenic mice overexpressing human $\operatorname{PrP}^{\mathrm{C}}$ M129. The cases were selected based upon the amount of $\mathrm{PrP}^{\mathrm{Sc}}$-M129 present in the sample, which ranged from 100 to $29 \%$ of the total $\operatorname{PrP}^{\mathrm{Sc}}$ and represented 4 different neuropathological subtypes of CJD (Tables 1 and 2). All cases had detectable, but variable, levels of $\operatorname{PrP}^{\mathrm{Sc}}$ as determined by mass spectroscopy (Table 1 and [28]) and western blot [28]. Using the RT-QuIC endpoint titration assay, most of the cases had similar prion seeding activities (Table 1) suggesting that they had similar levels of prion infectivity [45].

Brain homogenate samples from the cerebral cortex $(\mathrm{CC})$ or the cerebellar cortex $(\mathrm{CbC})$ were inoculated intracranially into two different strains of transgenic mice over-expressing human $\operatorname{PrP}^{\mathrm{C}}$-M129 [37], tgRM and tg66. Since both mouse strains are homozygous for $\operatorname{PrP}^{\mathrm{C}}$-M129, we hypothesized that they would be more susceptible to heterozygous CJD isolates containing

Table $1 \mathrm{PrP}^{\mathrm{SC}}$ abundance and prion seeding activity in CJD brain homogenate samples inoculated into transgenic mice

\begin{tabular}{llll}
\hline Case \# $^{\text {a }}$ & Subtype $^{a}$ & $\operatorname{PrP}^{\text {Sc }}(\mathrm{SpC})^{\mathrm{b}}$ & $\mathrm{SD}_{50} / \mathrm{g}^{\mathrm{c}}$ \\
\hline Control & $\mathrm{MM} 1$ & $\mathrm{ND}$ & $>5 \times 10^{9}$ \\
3 & $\mathrm{MV} 1+2 \mathrm{C}$ & $280 \pm 103$ & $5 \times 10^{9}$ \\
4 & $\mathrm{MV} 1+2 \mathrm{C}$ & $48 \pm 9$ & $9 \times 10^{7}$ \\
$9 \mathrm{CC}$ & $\mathrm{MV} 2 \mathrm{~K}+2 \mathrm{C}$ & $56 \pm 12$ & $8.9 \times 10^{10}$ \\
$9 \mathrm{CbC}$ & $\mathrm{MV} 2 \mathrm{~K}+2 \mathrm{C}$ & $126 \pm 15$ & $2.8 \times 10^{10}$ \\
12 & $\mathrm{MV} 2 \mathrm{~K}+2 \mathrm{C}$ & $90 \pm 4$ & $1.6 \times 10^{9}$ \\
19 (iCJD) & $\mathrm{MV} 2 \mathrm{~K}$ & $133 \pm 19$ & $3.5 \times 10^{11}$ \\
10 & $\mathrm{MV} 2 \mathrm{~K}$ & $175 \pm 19$ & $1.2 \times 10^{11}$ \\
20 (iCJD) & $\mathrm{MV} 2 \mathrm{~K}$ & $171+44$ & $1.6 \times 10^{11}$ \\
7 & $\mathrm{MV} 2 \mathrm{~K}$ & $581 \pm 89$ & $2.8 \times 10^{11}$ \\
18 (iCJD) & MV2K & $65 \pm 7$ & $2.8 \times 10^{11}$ \\
11 & MV2C & $290 \pm 9$ & $3.4 \times 10^{10}$ \\
\hline
\end{tabular}

${ }^{\mathrm{a}}$ Neuropathological subtype of cases originally described in [28]. All cases are sCJD except where noted as iCJD. CC cerebral cortex, CbC cerebellar cortex ${ }^{\mathrm{b}} \mathrm{SpC}$ spectral counts. Total number of $\mathrm{PrP}^{\mathrm{SC}}$ peptides as determined by mass spectrometry of phosphotungstic acid precipitated CJD brain material For mean + standard deviation in previous sentence, please underline the + sign. are adapted from [28]

${ }^{c} \mathrm{SD}_{50} / \mathrm{g}=$ prion seeding doses (SD) yielding $50 \%$ positive wells in replicate RTQulC reactions per $1 \mathrm{~g}$ of MV brain homogenate [45]. Values were calculated from 3 independent end-point titration experiments 
Table 2 Transmission of sCJD and iCJD with variable PrP ${ }^{S C}$ allotypes into tg66 and tgRM mice overexpressing human PrPC-M129

\begin{tabular}{|c|c|c|c|c|c|c|}
\hline \multirow[b]{2}{*}{ Case $\#^{\mathbf{a}}$} & \multirow[b]{2}{*}{ Subtype ${ }^{\mathbf{b}}$} & \multirow[b]{2}{*}{$\operatorname{PrP}^{\mathrm{Sc}}-\mathrm{M} 129^{\mathbf{C}}$} & \multicolumn{2}{|l|}{$\operatorname{tg} 66$} & \multicolumn{2}{|l|}{$\operatorname{tgRM}$} \\
\hline & & & $\left.\overline{\mathrm{DP}}\right|^{\mathbf{d}}$ & $\overline{\text { Clin/total }^{\mathbf{e}}}$ & $\left.\overline{\mathrm{DP}}\right|^{\mathbf{d}}$ & Clin/total $^{\mathbf{e}}$ \\
\hline Control & MM1 & 100 & $187 \pm 13$ & 9/9 & $211 \pm 11$ & $8 / 8$ \\
\hline 3 & $\mathrm{MV} 1+2 \mathrm{C}$ & $100 \pm 0^{* * * *}$ & $196 \pm 19$ & $8 / 8$ & $218 \pm 13$ & $7 / 8$ \\
\hline 4 & $\mathrm{MV} 1+2 \mathrm{C}$ & $34 \pm 5$ & $>611$ & $0 / 7$ & $>651$ & $0 / 6$ \\
\hline $9(C C)$ & $\mathrm{MV} 2 \mathrm{~K}+2 \mathrm{C}$ & $82 \pm 8^{* *}$ & $>502$ & $0 / 5$ & $>662$ & $0 / 7$ \\
\hline 9 (CbC) & $\mathrm{MV} 2 \mathrm{~K}+2 \mathrm{C}$ & $33 \pm 8$ & $488 \pm 17$ & $5 / 5$ & $519 \pm 26$ & $2 / 4$ \\
\hline 12 & $\mathrm{MV} 2 \mathrm{~K}+2 \mathrm{C}$ & $29 \pm 20$ & $497 \pm 132$ & $2 / 5$ & 471 & $1 / 7$ \\
\hline 19 (iCJD) & MV2K & $66 \pm 4^{* * *}$ & $184 \pm 2$ & $3 / 3$ & $214 \pm 9$ & $7 / 7$ \\
\hline 10 & MV2K & $43 \pm 2$ & $407 \pm 36$ & $7 / 7$ & $503 \pm 54$ & $5 / 6$ \\
\hline 20 (iCJD) & MV2K & $39 \pm 6$ & $482 \pm 34$ & $2 / 7$ & 373 & $1 / 5$ \\
\hline 7 & MV2K & $38 \pm 18$ & $398 \pm 13$ & $6 / 6$ & $448 \pm 18$ & $4 / 5$ \\
\hline 18 (iCJD) & MV2K & $36 \pm 5$ & $238 \pm 17$ & $5 / 8$ & $296 \pm 46$ & $4 / 7$ \\
\hline 11 & MV2C & $85 \pm 1$ & $401 \pm 21$ & $2 / 8$ & $>790$ & $0 / 8$ \\
\hline
\end{tabular}

${ }^{a}$ Neuropathological subtype of cases originally described in [28]. All cases are SCJD except where noted as iCJD. CB cerebellar cortex, CC cerebral cortex ${ }^{b}$ Cases originally described in [28]. MV2K $=$ CJD subtype MV2 with kuru (K) plaques; $2 \mathrm{C}=$ Type 2 PrP ${ }^{\mathrm{Sc}}$ in the cortex

${ }^{C}$ Percentage of $\mathrm{PrP}^{\mathrm{Sc}}$ in the inoculum which is $\mathrm{PrP}^{\mathrm{Sc}}-\mathrm{M} 129$ shown as mean + standard deviation. Data adapted from [28]. ${ }^{* * * *} p=0.0001$ versus case 4 by unpaired student's t-test; ${ }^{* * *} p=0.02$ versus case $10,0.007$ versus case $20,0.009$ versus case 7 , and 0.003 versus case 18 using Tukey's multiple comparisons test; ${ }^{* *} p=0.01$ versus case $9(\mathrm{CbC})$ and 12 using Tukey's multiple comparisons test

${ }^{\mathrm{d}} \mathrm{DPI}=$ mean days post-infection + standard deviation

${ }^{\mathrm{e}}$ Number of mice with clinical disease over total number of mice inoculated. Intercurrent deaths are not included

higher levels of $\operatorname{PrP}^{\mathrm{Sc}}-\mathrm{M} 129$. Transmission results are summarized in Table 2 and survival curves are shown in Fig. 1. For both mouse strains, the majority of cases inoculated caused clinical disease in at least some of the mice. As expected, disease incubation times were generally shorter in the tg66 mice which express higher levels of human $\operatorname{PrP}^{\mathrm{C}}-\mathrm{M} 129$ when compared to the tgRM mice [38]. Only two samples, case 4 and the CC sample from case 9, failed to cause any clinical disease within the lifetime of the host, although neuropathology and $\mathrm{PrP}^{\mathrm{Sc}}$ deposition were observed in a few mice suggesting that clinical disease may have eventually developed in those animals.

\section{The amount of PrP ${ }^{\mathrm{Sc}}-\mathrm{M} 129$ does not correlate with disease incubation time in tg66 or tgRM mice}

Consistent with previous transmission studies of heterozygous CJD cases [1, 2, 5, 23, 25], extended disease incubation times of more than 400 days were observed for most of the samples tested, although in many instances clinical signs of disease were observed in only a percentage of the total mice inoculated (Fig. 1 and Table 2). The exceptions were cases 3,18 , and 19 which caused clinical disease with incubation times of less than 400 days. In cases 3 and 19, $\mathrm{PrP}^{\mathrm{Sc}}$-M129 comprised 100 and $66 \%$, respectively, of the total $\operatorname{PrP}^{\mathrm{Sc}}$ while in case 18 $\mathrm{PrP}^{\mathrm{Sc}}-\mathrm{M} 129$ comprised only $36 \%$ of the total $\operatorname{PrP}^{\mathrm{Sc}}$. Thus, our transmission results would appear to be inconsistent with higher levels of $\mathrm{PrP}^{\mathrm{Sc}}-\mathrm{M} 129$ generally being predictive of faster disease incubation times.
Indeed, two other MV heterozygous CJD samples with greater than $80 \% \mathrm{PrP}^{\mathrm{Sc}}$-M129 either did not cause disease (case 9, CC sample) or caused disease in only a minority of tg66 mice inoculated (case 11). A linear regression analysis comparing clinical disease incubation times to $\mathrm{PrP}^{\mathrm{Sc}}$-M129 levels confirmed that, for both mouse strains, there was a poor correlation between the amount of $\mathrm{PrP}^{\mathrm{Sc}}-\mathrm{M} 129$ in the heterozygous CJD sample and clinical disease incubation time (Fig. 2a). In addition, we found no linear correlation of total $\operatorname{PrP}^{\mathrm{Sc}}$ levels in the brain with clinical disease incubation time in either tg66 or tgRM mice (Fig. 2b). Thus, our data suggest that the observed differences in disease incubation time were unrelated to either $\mathrm{PrP}^{\mathrm{Sc}}-\mathrm{M} 129$ or total $\mathrm{PrP}^{\mathrm{Sc}}$ levels.

\section{CJD PrP ${ }^{S C}$ type is not maintained following transmission into tg66 and tgRM mice}

We next looked at the size of $\operatorname{PrP}^{\mathrm{Sc}}$ deposited in the brain. Previous studies have shown that inoculation of MM1, MV1, and MV2 cases of CJD into mice homozygous for $\operatorname{PrP}^{\mathrm{C}}$-M129 always resulted in the deposition of Type $1 \mathrm{PrP}^{\mathrm{Sc}}$ in the brains of recipient mice $[5,23,25]$. We also found that Type $1 \operatorname{PrP}^{\mathrm{Sc}}$ accumulated in tg66 and tgRM mice inoculated with both the MV1 (Fig. 3) and MV2K (Fig. 4) CJD subtypes. However, for two samples that did not transmit well to mice, cases 11 and 9 $\mathrm{CC}$, Type $2 \mathrm{PrP}^{\mathrm{Sc}}$ accumulated in at least one of the two recipient mouse lines inoculated (Fig. 3). While these data are consistent with Type $2 \operatorname{PrP}^{\mathrm{Sc}}$ inhibiting disease, it is important to note that accumulation of Type 1 

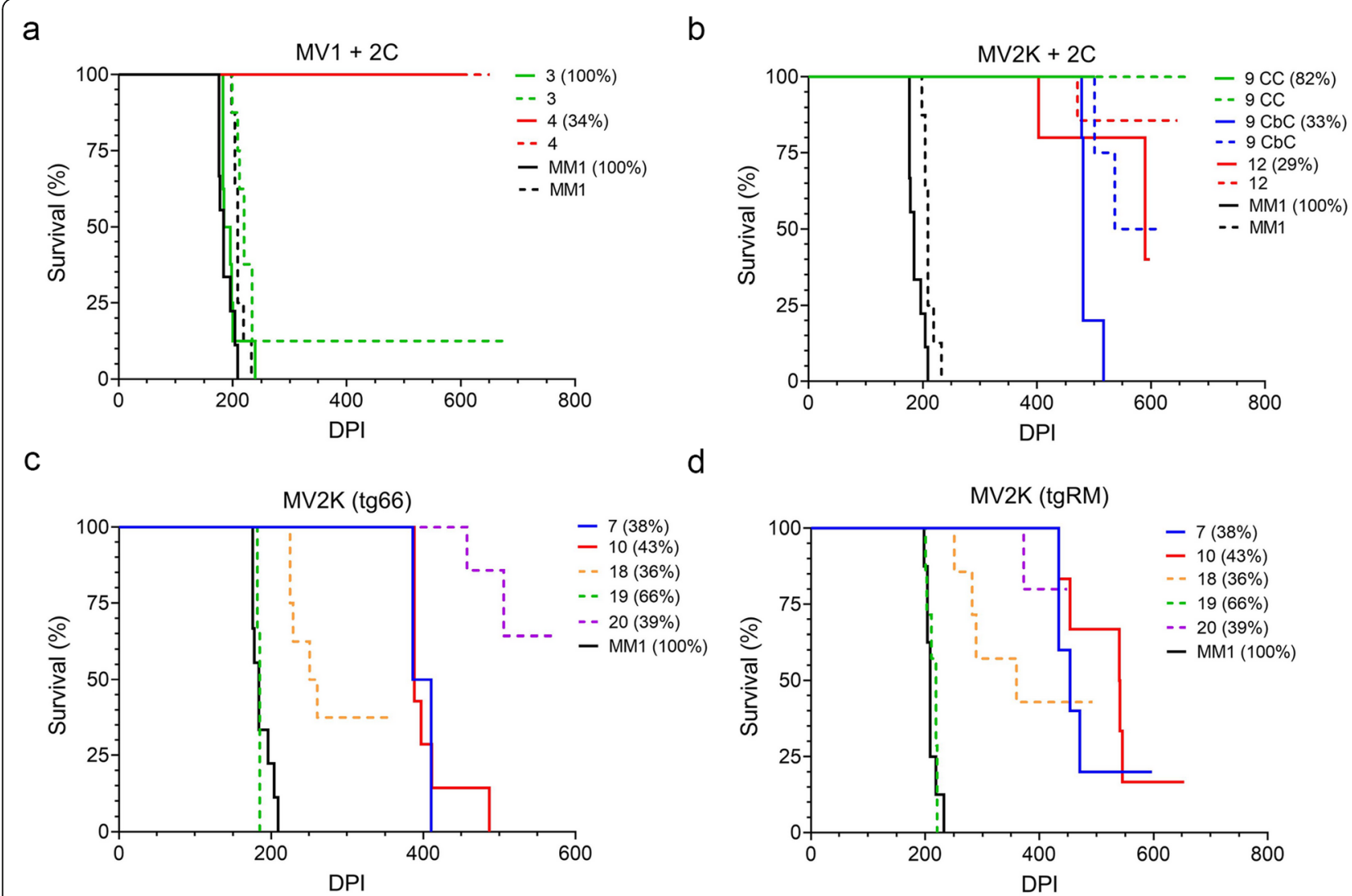

d

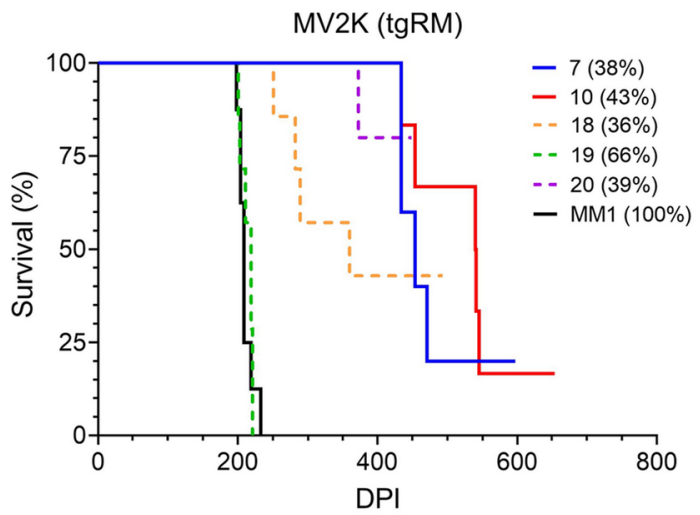

Fig. 1 Survival curves for tg66 and tgRM mice inoculated with MV heterozygous CJD brain homogenate containing variable levels of PrPSc-M129. Survival curves for mice inoculated with (a) MV1 $+2 \mathrm{C}$ or (b) MV2K $+2 \mathrm{C} \mathrm{SCJD}$. The percentage of PrPSC-M129 for each case inoculated is shown in parentheses to the right of the case number. Solid lines = tg66 mice; dashed lines = tgRM mice. Survival curves for (c) tg66 or (d) tgRM mice inoculated with MV2K CJD. The percentage of $\operatorname{PrP}^{\mathrm{SC}}-\mathrm{M} 129$ for each case inoculated is shown in parentheses to the right of the case number. Solid lines $=$ sCJD cases; dashed lines $=$ iCJD cases

$\operatorname{PrP}^{\mathrm{Sc}}$ was also observed in cases that transmitted poorly (Fig. 3a and Fig. 4, see cases 4 and 20). Thus, our results suggest that the type of $\operatorname{PrP}^{\mathrm{Sc}}$ deposited in the brain does not appear to correlate well with prolonged disease incubation times and/or lack of clinical disease. Moreover, they support a previous study [5] which suggested that the final $\operatorname{PrP}^{\mathrm{Sc}}$ type in recipient mice is not determined solely by the $\operatorname{PrP}^{\mathrm{Sc}}$ type in the inoculum but rather by interactions between the prion strain inoculated and the host.

\section{$\mathrm{PrP}^{\mathrm{SC}}$ allotype and disease phenotype in MV1 $+2 \mathrm{C} \mathrm{SCJD}$}

Previous studies have shown that efficient transmission of CJD into transgenic mice is influenced by the neuropathological subtype of CJD as well as by whether or not the inoculated mice express $\operatorname{PrP}^{\mathrm{C}}-\mathrm{M} 129$ and/or $\operatorname{PrP}^{\mathrm{C}}$ V129 [1, 2, 5, 9, 13, 23, 44]. Four different CJD subtypes were represented in the samples tested. We therefore analyzed whether, within a given CJD subtype, $\mathrm{PrP}^{\mathrm{Sc}}$ M129 was potentially influencing transmission into tg66 and tgRM mice. Since only a single case of MV2C was available (Table 2), this subtype was not included in the analysis.

Sporadic CJD subtype MV1 $+2 \mathrm{C}$, which is neuropathologically similar to MM1 sCJD [33], was represented by two cases that differed significantly in the amount of $\mathrm{PrP}^{\mathrm{Sc}}-\mathrm{M} 129$ present (Table 2). Case 3, where $\mathrm{PrP}^{\mathrm{Sc}}-\mathrm{M} 129$ represented $100 \%$ of the total $\mathrm{PrP}^{\mathrm{Sc}}$, caused clinical disease when inoculated into both tg66 and tgRM mice with incubation times indistinguishable from that of MM1 sCJD (Table 2 and Fig. 1a). Case 4, where $\mathrm{PrP}^{\mathrm{Sc}}-\mathrm{M} 129$ represented only $34 \%$ of the total $\mathrm{PrP}^{\mathrm{Sc}}$, did not cause clinical disease in either mouse strain (Table 2 and Fig. 1a). It was possible that the slightly higher seeding activity of case 3 (Table 1) accounted for its shorter incubation time and higher disease transmissibility. However, since cases 3 and 4 were classified as the same histopathological subtype [28], the starting seeding activity or titer should not influence the final neuropathological profile and pattern of $\operatorname{PrP}^{\mathrm{Sc}}$ deposition. We therefore analyzed the neuropathological features of both cases following transmission into transgenic mice. 


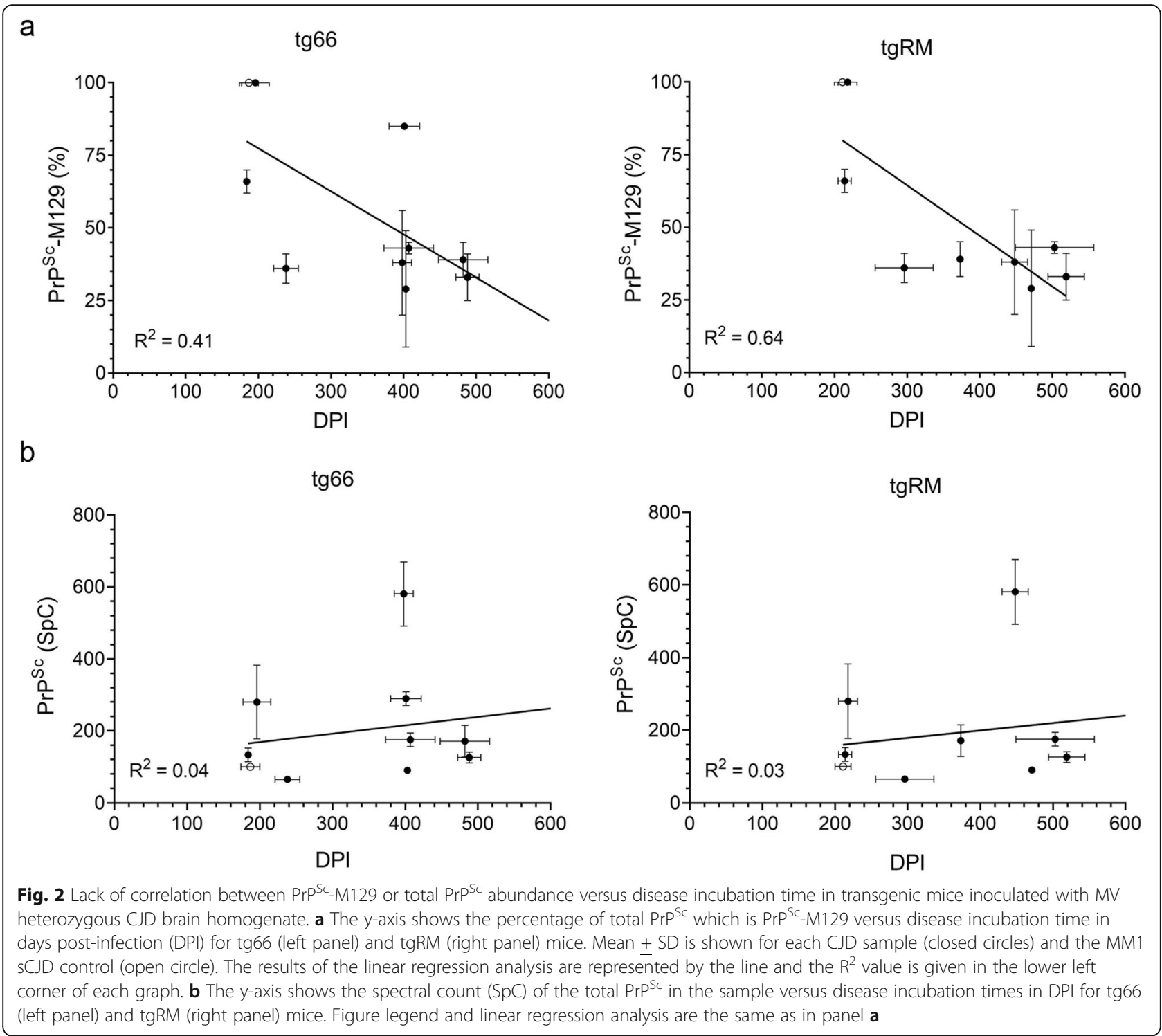

In general, the neuropathological features were similar in both tg66 and tgRM mice (Supplementary Table 1), and only results from tg66 mice are shown for most of the CJD subtypes inoculated.

Spongiform change was present in the hippocampus and granular layer of the cerebellum and was more severe in the cortex in mice inoculated with case 4 when compared to case 3, which had less extensive vacuolation in the cortex and no spongiform change apparent in either the cerebellum or hippocampus (Fig. 5a). In terms of $\mathrm{PrP}^{\mathrm{Sc}}$ deposition, diffuse, punctate/synaptic $\mathrm{PrP}^{\mathrm{Sc}}$ was deposited in mice inoculated with both cases (Fig. 5b), but only case 4 had occasional plaque-like deposits as well as dense $\operatorname{PrP}^{\mathrm{Sc}}$ deposits in the hippocampus and granular layer of the cerebellum (Fig. 5b). In addition, both cases were clearly neuropathologically distinct from MM1 sCJD which was characterized by mild to moderate spongiform change and diffuse, synaptic/ punctate deposition of $\mathrm{PrP}^{\mathrm{Sc}}$ in both mouse lines. (Supplementary Table 1, Supplementary Fig. 1 and Fig. 2). Thus, the data suggest that the prions in cases 3 and 4 have distinct properties that differ not only from each other but also from the MM1 subtype of CJD prions to which they are neuropathologically similar [33]. Our data show a lack of consistency in transmission properties of cases of MV1 $+2 \mathrm{C} \mathrm{sCJD}$ where the abundance of $\mathrm{PrP}^{\mathrm{Sc}}-\mathrm{M} 129$ is significantly different and suggest that there is greater phenotypic variability within this CJD subtype than has been previously recognized.

\section{$\mathrm{PrP}^{\mathrm{SC}}$ allotype and disease in MV2K sporadic and iatrogenic CJD}

We next analyzed whether the $\mathrm{PrP}^{\mathrm{Sc}}$ allotype ratio correlated with the transmission properties of the 5 cases of 


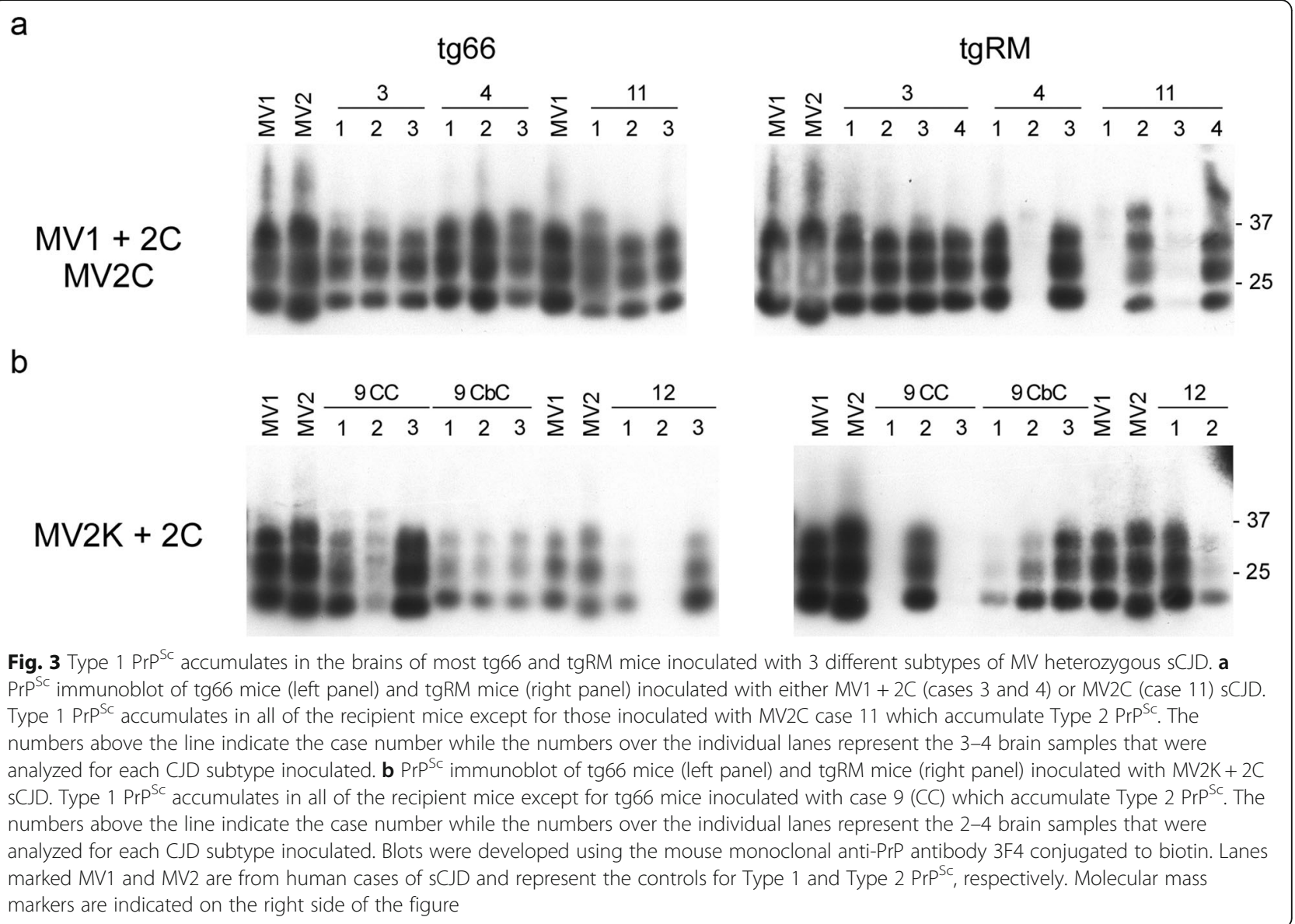

MV2K inoculated. The two sporadic CJD MV2K cases, which contained similar levels of $\mathrm{PrP}^{\mathrm{Sc}}$-M129 (Table 2), caused clinical disease with similar incubation times in all of the tg66 mice (Table 2, Fig. 1c) and the majority of tgRM mice inoculated (Table 2, Fig. 1d). Pathologically, the two cases were indistinguishable and were characterized by mild to moderate spongiform change in both mouse strains particularly in the thalamus and corpus callosum (Supplementary Table 1, Fig. 6a). PrP $\mathrm{P}^{\mathrm{Sc}}$ deposition was characterized mainly by a mix of perivacuolar $\operatorname{PrP}^{\mathrm{Sc}}$ and scattered $\operatorname{PrP}^{\mathrm{Sc}}$ amyloid plaques in many areas of the brain including very large plaques in the corpus callosum (Fig. 7a).

The other three MV2K samples inoculated were human growth hormone-related cases of iatrogenic CJD from the UK. Unexpectedly, these cases differed in their presentation from the sCJD MV2K samples inoculated. Case 19, which had significantly more $\operatorname{PrP}^{\mathrm{Sc}}-\mathrm{M} 129$ than the other $4 \mathrm{MV} 2 \mathrm{~K}$ cases (Table 2), was also the only MV2K sample which caused clinical disease in all tgRM and tg66 mice inoculated (Fig. 1c and d) with incubation times indistinguishable from that of MM1 sCJD (Table 2). Despite the different disease incubation times, the neuropathological features for MV2K cases 18 and 19 were similar and distinct from that of the two sCJD MV2K cases. Mild to moderate spongiform change was observed in most regions of the brain (Fig. 6b) and $\mathrm{PrP}^{\mathrm{Sc}}$ was deposited in a diffuse, punctate/synaptic pattern (Fig. 7b) with amyloid plaques limited to the area around the needle scar (Supplementary Fig. 3). Interestingly, $\operatorname{PrP}^{\mathrm{Sc}}$ deposition in case 20 differed somewhat in that synaptic $\operatorname{PrP}^{\mathrm{Sc}}$ deposition was less prominent and plaque-like deposits were observed in multiple brain regions (Fig. 7b). The combined transmission data from the $5 \mathrm{MV} 2 \mathrm{~K}$ samples are consistent with the possibility that a greater abundance of $\mathrm{PrP}^{\mathrm{Sc}}$-M129 correlates with faster disease incubation times in this CJD subtype. The data also show that prions from sporadic versus iatrogenic cases of MV2K have different properties, suggesting that prions from iatrogenic cases of MV2K CJD are either not derived from sporadic MV2K prions or were altered by passage through humans.

\section{Brain regions from a single patient which differ in $\mathrm{PrP}^{\mathrm{Sc}}$ allotype have prions with different transmission properties}

In our previous study, we found that the $\mathrm{PrP}^{\mathrm{Sc}}$ allotype ratio could differ significantly between brain regions 


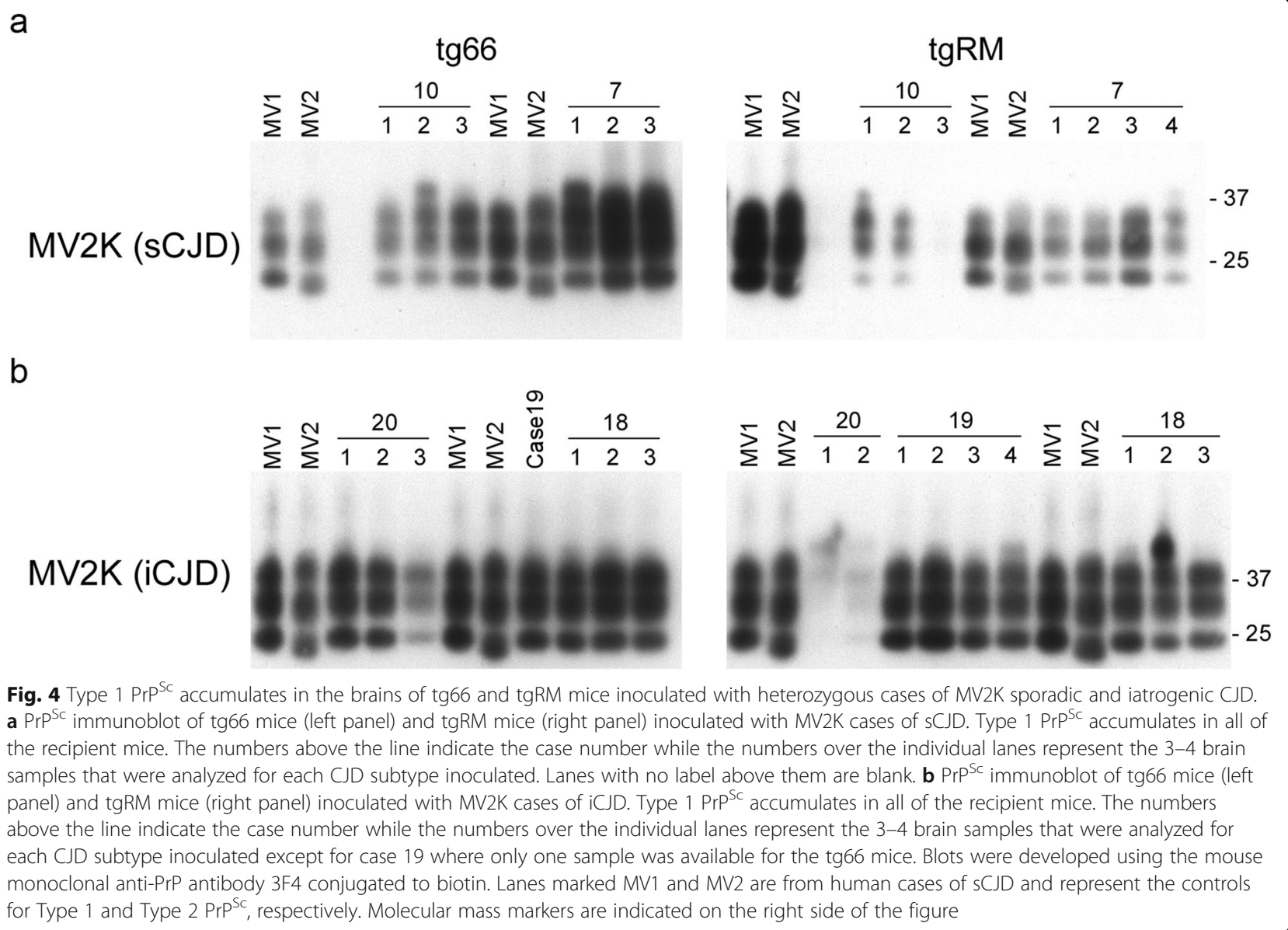

within the same patient [28] and that these differences were associated with different patterns of $\mathrm{PrP}^{\mathrm{Sc}}$ deposition within the brain [28]. In order to determine whether or not the transmission properties of the prions in these brain regions also differed, we inoculated two different brain regions from a single $\mathrm{MV} 2 \mathrm{~K}+2 \mathrm{C}$ patient (case 9) into tg66 and tgRM mice. The cerebral cortex sample from case 9 (9 CC) did not cause clinical disease in either tg66 or tgRM mice (Table 2, Fig. 1b) even though it had a statistically higher abundance of $\operatorname{PrP}^{\mathrm{Sc}}$ M129 when compared to the other MV2K $+2 \mathrm{C}$ samples inoculated. By contrast, a cerebellar cortex sample from the same case $(9 \mathrm{CbC})$ caused clinical disease in all tg66 mice (Table 2, Fig. 1b) and in 50\% of the tgRM mice inoculated, even though it had a lower abundance of $\mathrm{PrP}^{\mathrm{Sc}}$-M129 (Table 2). These results are the opposite of those for cases 3 and 19 where significantly higher levels of $\mathrm{PrP}^{\mathrm{Sc}}-\mathrm{M} 129$ relative to $\mathrm{PrP}^{\mathrm{Sc}}-\mathrm{V} 129$ were associated with faster disease incubation times (Table 2). Thus, our data suggest not only that prions in two different brain regions from the same patient have different transmission properties but also that the abundance of $\operatorname{PrP}^{\mathrm{Sc}}$ M129 in heterozygous cases of CJD is not a reliable predictor of disease incubation time.
Interestingly, samples $9 \mathrm{CC}$ and $9 \mathrm{CbC}$ also differed neuropathologically. Spongiform change tended to be more severe in the mice inoculated with the $\mathrm{CbC}$ sample (Supplementary Table 1, Fig. 8a). In addition, $\mathrm{PrP}^{\mathrm{Sc}}$ deposition and amyloid plaques were more prevalent in the cortex, thalamus, and hypothalamus in the $9 \mathrm{CbC}$ sample when compared to the CC sample where $\operatorname{PrP}^{\mathrm{Sc}}$ was primarily found in dense, perivacuolar deposits (Supplementary Table 1, Fig. 8b). The prevalence of amyloid plaques in transgenic mice inoculated with the cerebellar sample from case 9 is reflective of what was observed in the original human brain tissue where plaques were prominent in cerebellar tissue but not in cortical tissue [28]. The most striking difference between the two samples was in the septum where spongiform change and dense, perivacuolar deposits of $\operatorname{PrP}^{\mathrm{Sc}}$ were present in mice inoculated with the $\mathrm{CC}$ sample but were completely absent in mice inoculated with the $\mathrm{CbC}$ sample (Fig. $8 \mathrm{a}$ and $\mathrm{b})$. The transmission and neuropathological data together strongly suggest that, in heterozygous cases of SCJD, prions with different infectious properties can arise in brain regions with different $\operatorname{PrP}^{\mathrm{Sc}}$ allotypes. 


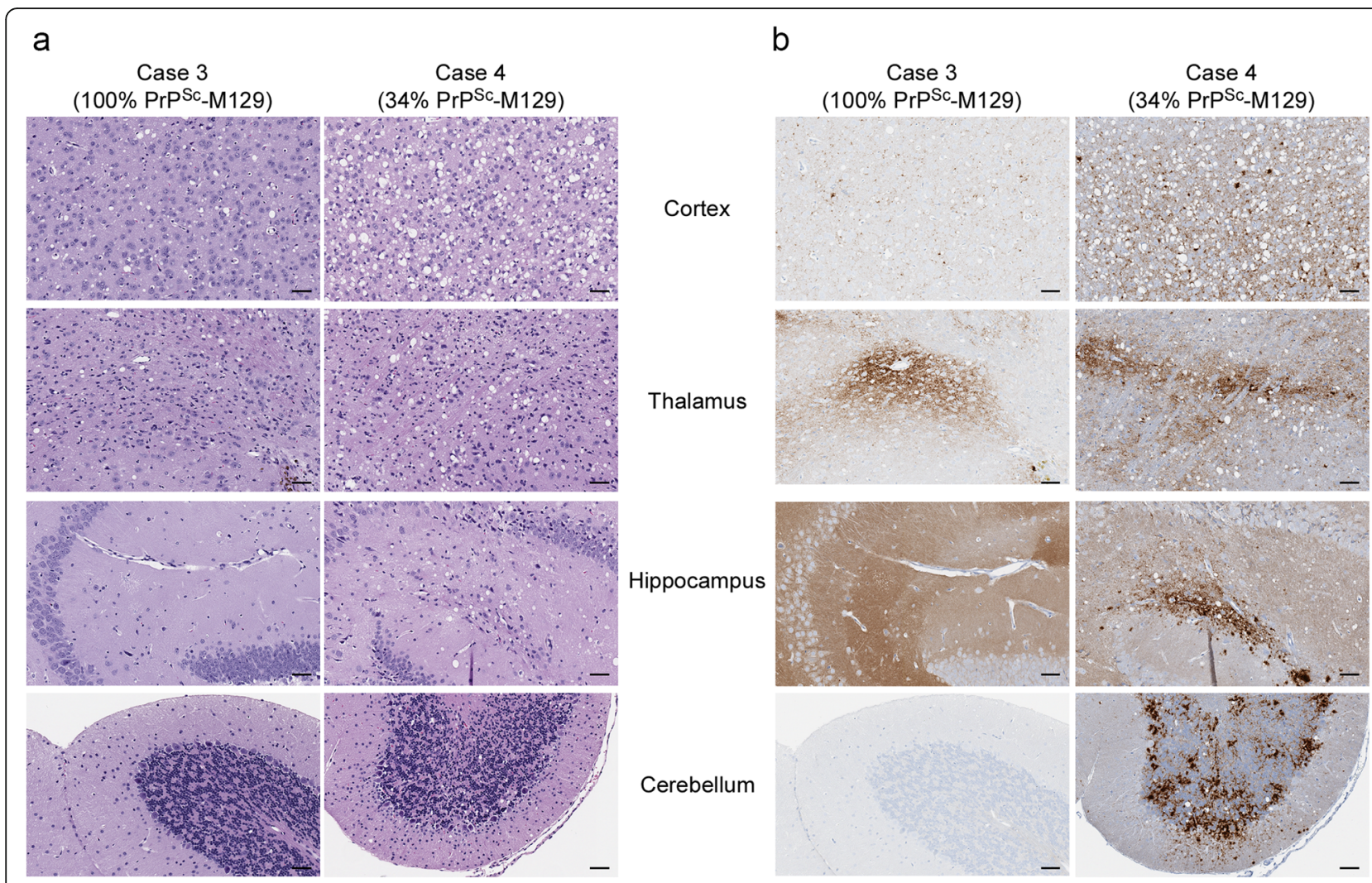

Fig. 5 Spongiform change and PrP ${ }^{S C}$ deposition differ in the brains of tg66 mice inoculated with cases of MV1 $+2 C$ with different PrP $P^{S C}$ allotype ratios. a H\&E staining of tg66 mice inoculated with MV1 $+2 C$ cases 3 (183 dpi) and 4 ( 479 dpi). The mean percentage of $\operatorname{PrP}^{{ }^{S C}}{ }_{-M 12}{ }^{2}$ in each sample is given under the case number. $\mathbf{b} \mathrm{PrP}^{\mathrm{Sc}}$ staining using the mouse monoclonal anti-PrP antibody $3 \mathrm{~F} 4$ conjugated to biotin. The fields are matched to those shown in panel $\mathbf{a}$. The brain regions shown are indicated in the middle of the figure. For all panels, scale bar $=50 \mu \mathrm{m}$

A third MV2K $+2 \mathrm{C}$ sample was inoculated that had different transmission properties when compared to the two samples from case 9 . Case 12 caused disease in at least some tg66 and tgRM mice inoculated but only after a prolonged incubation time (Table 2, Fig. 1b). Strikingly, the neuropathology and $\operatorname{PrP}^{\mathrm{Sc}}$ deposition induced by the case 12 sample varied depending upon the mouse strain. In tgRM mice, mild spongiform change was observed (Supplementary Table 1, Supplementary Fig. 4a) while diffuse $\mathrm{PrP}^{\mathrm{Sc}}$ deposition was observed along with large amyloid plaques (Supplementary Fig. 4b). By contrast, in the single tg66 mouse where pathology was present, spongiform change was more extensive (Supplementary Table 1, Supplementary Fig. $4 \mathrm{~b}$ ) and $\mathrm{PrP}^{\mathrm{Sc}}$ was deposited in a diffuse, synaptic pattern with no amyloid plaques apparent (Supplementary Fig. 4b). Overall, our data show that there can be considerable variability in the transmission properties of $\mathrm{MV} 2 \mathrm{~K}+2 \mathrm{C}$ prions. Moreover, they suggest prions with different transmission properties exist even within well-defined neuropathological subtypes of CJD and that host factors other than $\operatorname{PrP}^{\mathrm{C}}$ sequence can significantly influence the final prion disease phenotype.

\section{Discussion}

In transgenic mice expressing only human $\operatorname{PrP}^{\mathrm{C}}-\mathrm{M} 129$, a mismatch at amino acid 129 in the inoculum can influence disease incubation time. Thus, the MM1 subtype of sCJD transmits most efficiently into transgenic mice homozygous for human $\operatorname{PrP}^{\mathrm{C}}-\mathrm{M} 129$ [2, 5, 25, 43]. However, transmission of MV heterozygous cases of CJD can vary by incubation time and CJD type [5, 20, 23, 25, 44]. Our hypothesis was that the variable transmission efficiency of heterozygous cases of SCJD into transgenic mice expressing human $\operatorname{PrP}^{\mathrm{C}}-\mathrm{M} 129$ was determined by the $\operatorname{PrP}^{\mathrm{Sc}}$ allotype ratio in the sample inoculated. Our expectation was therefore that MV heterozygous CJD samples with statistically higher levels of $\mathrm{PrP}^{\mathrm{Sc}}-\mathrm{M} 129$ would transmit disease more efficiently into our mice than samples where $\operatorname{PrP}^{\mathrm{Sc}}-\mathrm{V} 129$ predominated. This hypothesis was supported by data from two of the SCJD subtypes we tested, MV1 $+2 \mathrm{C}$ and MV2K, but did not hold true for the MV2K $+2 \mathrm{C}$ subtype. In the latter subtype, a greater abundance of $\mathrm{PrP}^{\mathrm{Sc}}-\mathrm{M} 129$ in the sample relative to $\mathrm{PrP}^{\mathrm{Sc}}-\mathrm{V} 129$ led to prolonged incubation times and had a negative effect on disease transmission. Thus, our data suggest that the relative amount of $\mathrm{PrP}^{\mathrm{Sc}}-\mathrm{M} 129$ 


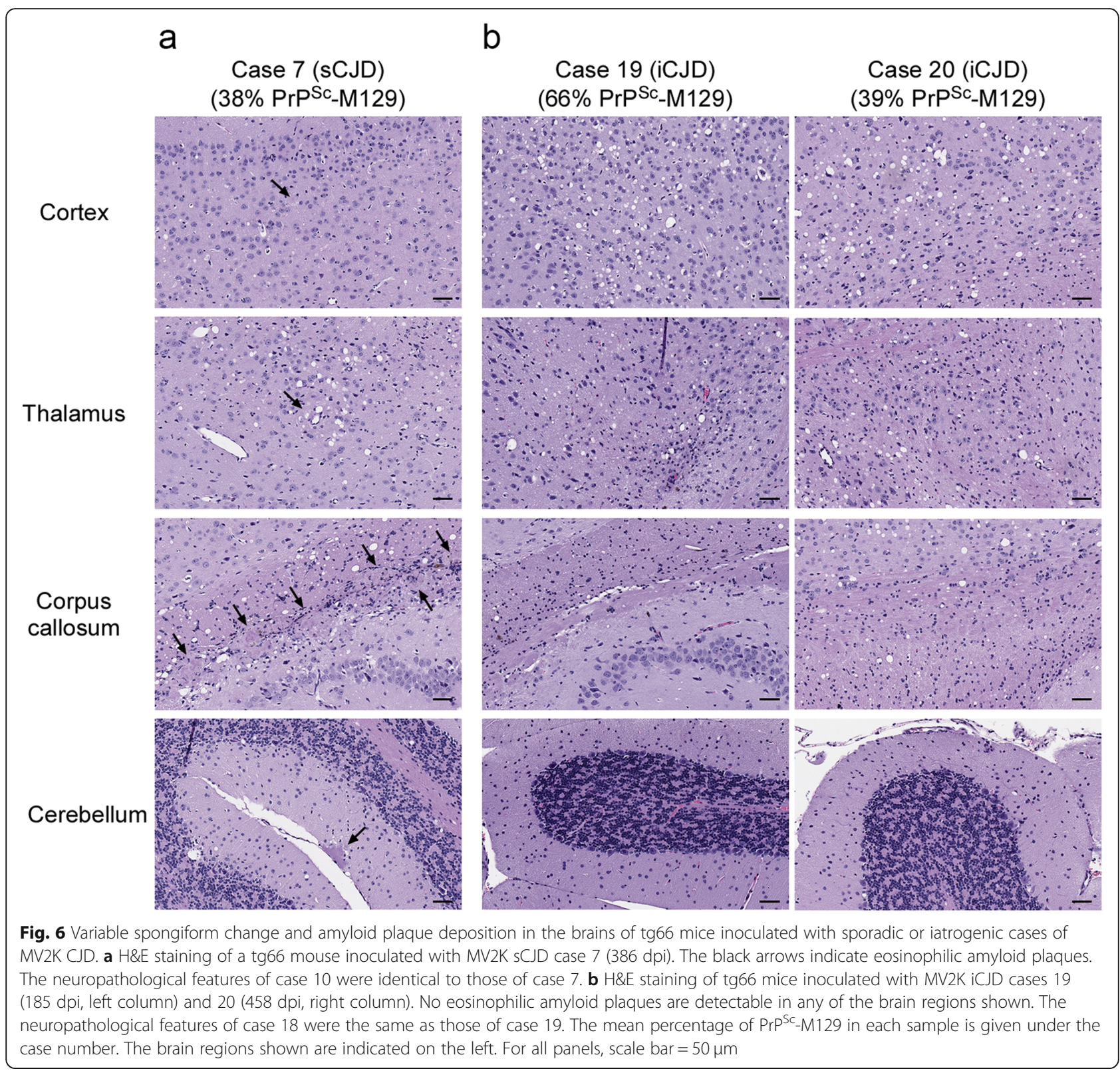

in cases of heterozygous CJD is not predictive of disease incubation time even when the amino acid at codon 129 is the same in both the inoculum and host.

Earlier studies have suggested that a methionine or valine at codon 129 influences how $\operatorname{PrP}^{\mathrm{Sc}}$ is deposited $[14,16,21,27,42]$. A valine at residue 129 is associated with plaque formation and a longer clinical disease course [21] while a methionine at residue 129 is associated with a more synaptic pattern of $\operatorname{PrP}^{\mathrm{Sc}}$ deposition and shorter clinical course [21]. Our transmission data suggest that $\operatorname{PrP}^{\mathrm{Sc}}$ allotype ratio may impact the pattern of $\operatorname{PrP}^{\mathrm{Sc}}$ deposition in a similar way. In mice inoculated with samples consisting entirely of $\operatorname{PrP}^{\mathrm{Sc}}-\mathrm{M} 129, \operatorname{PrP}^{\mathrm{Sc}}$ was deposited in a diffuse, punctate/synaptic pattern with no amyloid plaques detected. In the MV heterozygous CJD cases where $\mathrm{PrP}^{\mathrm{Sc}}-\mathrm{V} 129$ was present, amyloid plaques were detected but their prevalence and location varied. In samples where $\mathrm{PrP}^{\mathrm{Sc}}-\mathrm{V} 129$ comprised the majority of total $\operatorname{PrP}^{\mathrm{Sc}}$, amyloid plaques and plaque-like deposits were more common and more widely distributed than in samples where $\mathrm{PrP}^{\mathrm{Sc}}-\mathrm{V} 129$ represented less than half of the total $\mathrm{PrP}^{\mathrm{Sc}}$ in the samples. In these latter samples, large plaques were found almost exclusively around the needle scar (Supplementary Fig. 3) suggesting a possible lack of spread from the site of inoculation. Thus, we hypothesize that, in MV heterozygous cases of CJD, plaque phenotype and plaque load may reflect the relative abundance of $\mathrm{PrP}^{\mathrm{Sc}}-\mathrm{V} 129$ present. 


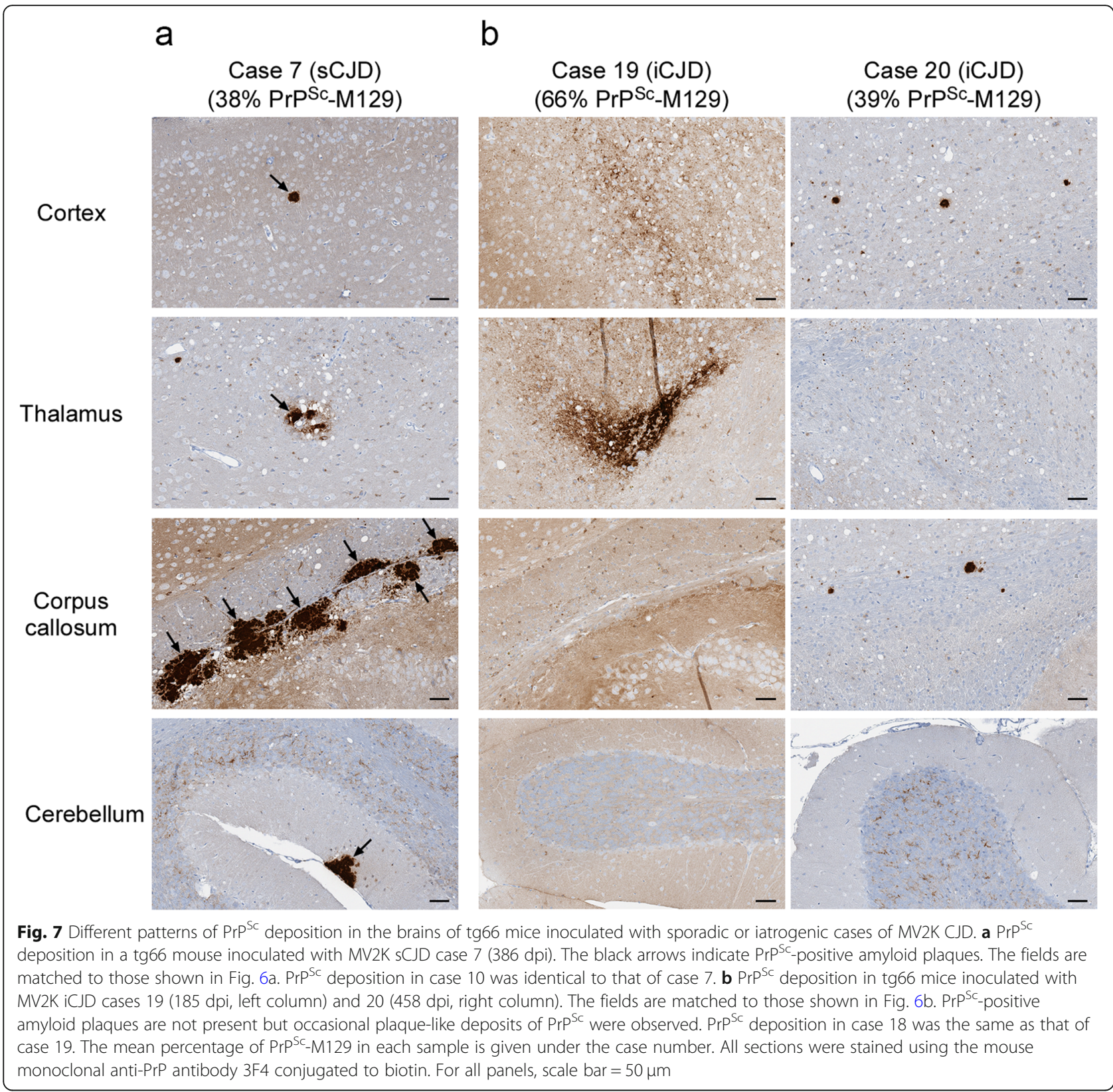

Support for this hypothesis was provided by the pattern of $\operatorname{PrP}^{\mathrm{Sc}}$ deposition in mice inoculated with two different brain regions from a case of $\mathrm{MV} 2 \mathrm{~K}+2 \mathrm{C}$. $\mathrm{PrP}^{\mathrm{Sc}}$ in the cerebellar cortex sample $9 \mathrm{CbC}$ was composed primarily of $\operatorname{PrP}^{\mathrm{Sc}}-\mathrm{V} 129$ and led to $\operatorname{PrP}^{\mathrm{Sc}}$ amyloid plaques as well as perivacuolar $\mathrm{PrP}^{\mathrm{Sc}}$ deposition in multiple brain regions of the recipient mice. By contrast, $\operatorname{PrP}^{\mathrm{Sc}}$ in the cerebral cortex sample $9 \mathrm{CC}$ was composed primarily of $\mathrm{PrP}^{\mathrm{Sc}}-\mathrm{M} 129$ and was associated mainly with synaptic and perivacuolar $\mathrm{PrP}^{\mathrm{Sc}}$ deposition (Fig. $8 \mathrm{~b}$ ) with dense plaques found only around the needle scar (Supplementary Fig. 3). These findings were consistent with the pattern of $\mathrm{PrP}^{\mathrm{Sc}}$ deposition in the original brain material from case 9 [28]. In that case, $\mathrm{PrP}^{\mathrm{Sc}}-\mathrm{V} 129$ was significantly more abundant in the cerebellum where plaques were a primary feature of $\operatorname{PrP}^{\mathrm{Sc}}$ deposition while $\operatorname{PrP}^{\mathrm{Sc}}$ M129 was significantly more abundant in the cortex where $\mathrm{PrP}^{\mathrm{Sc}}$ deposition was primarily synaptic [28].

The $\mathrm{CC}$ and $\mathrm{CbC}$ samples from case 9 led to patterns of $\mathrm{PrP}^{\mathrm{Sc}}$ deposition in mice that differed from each other but were similar to that in the brain of the original patient. This strongly suggests that prions with distinctive properties, i.e. prion strains, are being propagated in different regions of the brain. Our data are also consistent with the fact that multiple strains of prions have been isolated from a single brain $[4,15]$. However, the long 


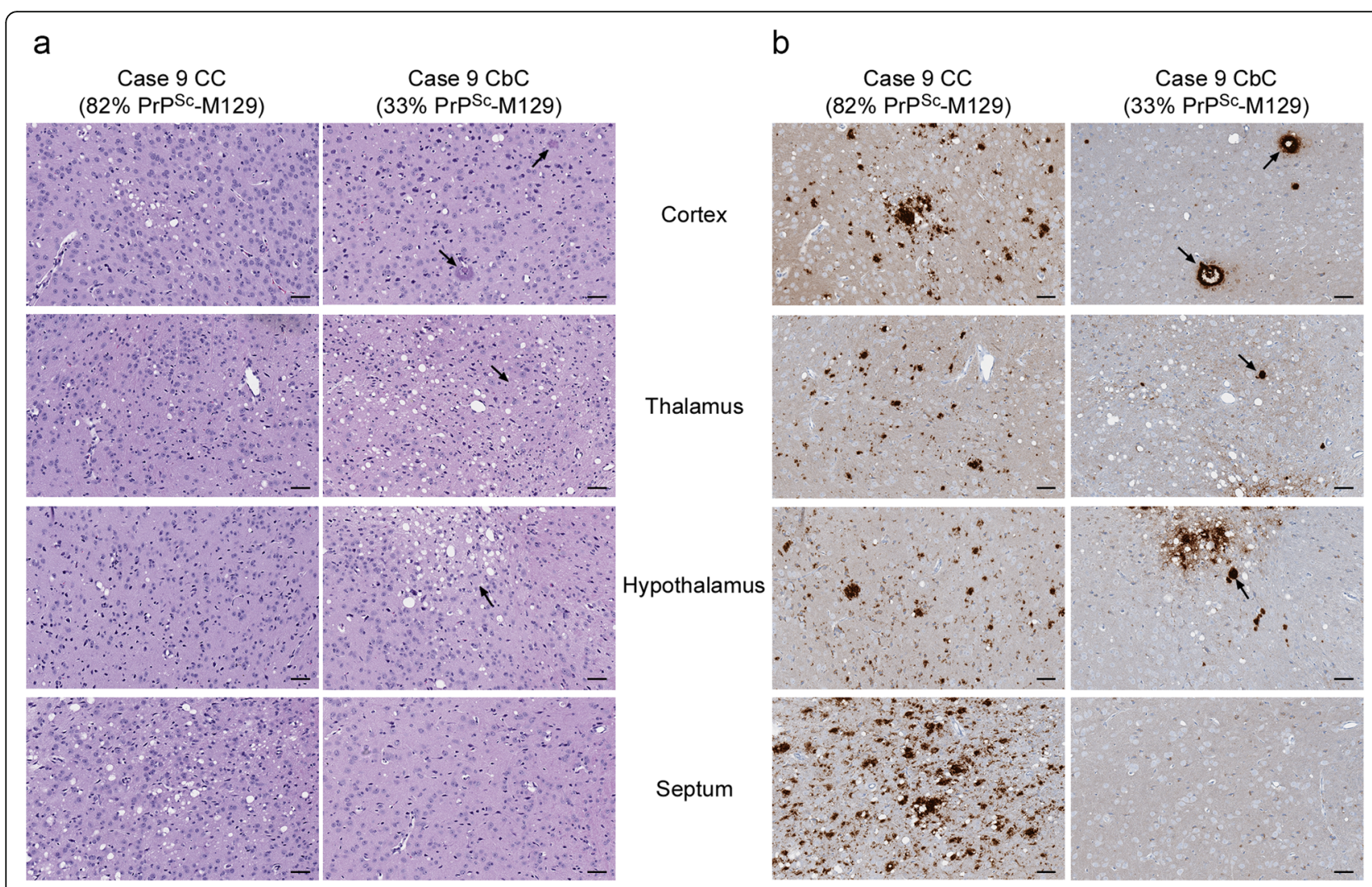

Fig. 8 Spongiform change and $\operatorname{PrP}{ }^{S c}$ deposition differ in the brains of tg66 mice inoculated with two different brain regions from a single case of MV2K + 2C sCJD. a H\&E staining of a tg66 mouse inoculated with MV2K + 2C sCJD case 9 CC (502 dpi, left column) or 9 CbC (481 dpi, right column). The black arrows indicate eosinophilic amyloid plaques. b PrP ${ }^{S c}$ deposition in a tg66 mouse inoculated with MV2K $+2 C$ sCJD case 9 CC (502 dpi, left column) or 9 CbC (481 dpi, right column). The black arrows indicate PrPSc-positive amyloid plaques. The fields are matched to those shown in panel a. Sections were stained using the mouse monoclonal anti-PrP antibody $3 \mathrm{~F} 4$ conjugated to biotin. The mean percentage of PrPSc M129 in each sample is given under the case number. Brain regions shown are indicated in the middle of the figure. For all panels,

scale $\mathrm{bar}=50 \mu \mathrm{m}$

incubation time of sCJD makes it difficult to determine how different brain regions might give rise to different prion strains. One possibility is that, if a single spontaneous misfolding event were responsible for the initiation of SCJD, different selective pressures in the cortex versus the cerebellum could select for different prion strains. An alternative possibility is that more than one spontaneous misfolding event occurred, one in the cortex and one in the cerebellum, each of which gave rise to different prion strains. While admittedly speculative, the latter scenario raises the intriguing possibility that spontaneous formation of $\operatorname{PrP}^{\mathrm{Sc}}$ may not necessarily be a rare event in some individuals but rather a consequence of some other deficit in the protein folding/unfolding machinery that predisposes them to accumulating misfolded protein.

Previous studies have suggested that MV2K and MV2K $+2 \mathrm{C}$ sCJD act similarly when transmitted into transgenic mice expressing human $\operatorname{PrP}^{\mathrm{C}}-\mathrm{M} 129$. However, these studies were based on the results from a single case of each type [23]. The current study, where 3 samples of MV2K $+2 \mathrm{C}$ and 5 samples of MV2K CJD were tested, suggests a more complex picture. As discussed above, we observed phenotypic variability even within a particular CJD subtype. In the MV2K $+2 \mathrm{C}$ subtype, prions from two different brain regions of case 9 differed in their transmission phenotype while the pattern of $\mathrm{PrP}^{\mathrm{Sc}}$ deposition in case 12 differed between tg66 and tgRM mice (Supplementary Fig. 4). This variation in the transmission properties of different cases of MV2K + $2 \mathrm{C}$ makes it difficult to compare in any meaningful way with MV2K cases of CJD. In these latter cases, there was variation in disease phenotype depending upon whether they were from sporadic or iatrogenic CJD. This variability suggests that transmission of different isolates of $\mathrm{MV} 2 \mathrm{~K}$ and $\mathrm{MV} 2 \mathrm{~K}+2 \mathrm{C}$ into our transgenic mice may have led to the propagation of different prion strains. However, further passage in mice will be needed to determine whether or not the phenotypes we observed are both stable and faithfully propagated, key characteristics 
of prion strains. Overall, the variability we observed within and between subtypes that have been reported to be very similar again suggests a more complex picture of CJD transmission where CJD subtype, $\mathrm{PrP}^{\mathrm{Sc}}$ conformation, $\operatorname{PrP}^{\mathrm{Sc}}$ allotype, and the host likely all contribute to the final disease phenotype.

In the UK, the PRNP codon 129 genotype of the cohort of iCJD patients associated with exposure to prion-contaminated human growth hormone extracts is primarily $\mathrm{MV}$ heterozygous or $\mathrm{VV}$ homozygous, with only a small percentage of the patients being MM homozygous [6, 12, 40]. This PRNP genotype distribution is distinct from that of SCJD in the UK [6] as well as cohorts of human growth hormonerelated ICJD in France [6] and the US [7]. Based on these genotype differences, it has been suggested that UK human growth hormone-related iCJD was the result of exposure to a different prion strain $[6,7]$ than that responsible for human growth hormone related iCJD in France and the US.It was further proposed that either $\mathrm{MV}$ or $\mathrm{VV}$ prions were responsible for the UK cases [39, 40], with VV2 prions considered to be the most likely source [39]. Our results demonstrating that the transmission phenotype of MV2K prions from sCJD and iCJD differ would seem to argue against MV2K prions as being the source of infection for human growth hormone-related $\mathrm{iCJD}$ in the UK. Nonetheless, it's still possible that either VV2 prions were the source of infection or that passage through humans altered the properties of the original infectious prions leading to an $\mathrm{iCJD}$ MV2K prion strain or strains that do not recapitulate the sCJD MV2K phenotype when inoculated into transgenic mice over-expressing human $\operatorname{PrP}^{\mathrm{C}-} \mathrm{M} 129$.

\section{Conclusions}

$\mathrm{PrP}^{\mathrm{Sc}}$ allotype is not predictive of disease incubation time and is not the primary determinative driver of phenotype in heterozygous cases of CJD. However, it does appear to correlate with the type of $\operatorname{PrP}^{\mathrm{Sc}}$ deposited. Thus, when $\mathrm{PrP}^{\mathrm{Sc}}-\mathrm{V} 129$ predominates, $\mathrm{PrP}^{\mathrm{Sc}}$ plaques are common. We further conclude that, within a single patient brain, prions with different infectious properties can arise in brain regions with different $\mathrm{PrP}^{\mathrm{Sc}}$ allotypes. These data may help to explain why multiple prion strains can be isolated from a single brain. Finally, we conclude that MV2K prions from sCJD differ from iCJD MV2K prions, suggesting that sCJD MV2K may not have been the source of infection in human growth hormone related cases of iCJD in the UK. Overall, our data demonstrate that there is more heterogeneity in the transmission properties of CJD neurological subtypes than has been previously described and suggest a complex picture of CJD transmission where CJD subtype,
$\operatorname{PrP}^{\mathrm{Sc}}$ conformation, $\operatorname{PrP}^{\mathrm{Sc}}$ allotype, and the host likely all contribute to the final disease phenotype.

\section{Supplementary information}

Supplementary information accompanies this paper at https://doi.org/10. 1186/s40478-020-00958-X.

Additional file 1. Histopathological and neuropathological characteristics of tg66 and tgRM mice inoculated with either MM1 sCJD or MV heterozygous cases ofSCJD and iCJD with variable PrPSC allotypes.

\section{Abbreviations}

PrPC: normal prion protein; PrPSc: infectious prion protein; BSE: Bovine Spongiform Encephalopathy; NaCL: sodium chloride; KCL: potassium chloride; $\mathrm{PO}_{4}$ : phosphate; ThT: Thioflavin T; SD: seeding dose; SCJD: sporadic Creutzfeldt-Jakob Disease; iCJD: iatrogenic Creutzfeldt-Jakob Disease; CC: Cerebral cortex; CbC: Cerebellar cortex; RT-QulC: Real Time Quaking Induced Conversion; SpC: Spectral counts; DPI: Days post-infection; NBF: Normal buffered formalin; PBBS: Phosphate buffered balanced salts solution; PBS: Phosphate buffered saline; SDS: Sodium dodecyl sulfate; EDTA: Ethylenediaminetetraacetic acid; H\&E: Hamotoxylin and eosin; ThioS: Thioflavin S; PK: Proteinase K; PMSF: Phenylmethylsulfonyl fluoride; LDS: Lithium dodecyl sulfate; TBST: Tris buffered saline plus Tween

\section{Acknowledgments}

The authors would like to thank Nancy Kurtz and Lori Lubke for processing of samples for histology and Anita Mora and Austin Athman for help with the figures. The authors also thank Drs. Bruce Chesebro and Karin Peterson for critical reading of the manuscript.

\section{Authors' contributions}

AW performed all animal experiments and western blots, analyzed histopathological, transmission, and western blot data, and contributed to writing the manuscript. JRH performed and analyzed all RT-QuIC assays and contributed to writing the manuscript. KM performed control animal experiments. DLR and GZ provided critical human samples and contributed to writing the manuscript. SAP designed the study, performed statistical data analysis, analyzed histopathological, transmission, and western blot data, and wrote the manuscript. All authors read and approved the final manuscript.

\section{Funding}

This research was supported by a grant from the National Institutes of Health, National Institute of Allergy and Infectious Diseases, Division of Intramural Research, which had no role in the design of the study and collection, analysis, and interpretation of data or writing of the manuscript.

\section{Availability of data and materials}

Data sharing not applicable to this article as no datasets were generated or analysed during the current study.

\section{Ethics approval and consent to participate}

Human brain samples were obtained either from the National CJD Research \& Surveillance Unit Brain and Tissue Bank, which is part of the MRC Edinburgh Brain \& Tissue Bank (Edinburgh Brain Bank 16-ES-0084), UK, or from the University of Verona, Italy. These latter tissues were obtained at autopsy and sent to the Neuropathology Unit at the University of Verona for statutory definite diagnosis of CJD. Ethical approval for the acquisition and use of post-mortem human CJD brain samples was obtained from the National Institutes of Health (NIH) Office of Human Subject Research (Exempt $\# 11763$ and \#12725) and no patient identifiable data was transferred to the $\mathrm{NIH}$.

The animal experimental protocol was reviewed and approved by the Rocky Mountain Laboratories Animal Care and Use Committee. This study was carried out in strict accordance with the recommendations in the Guide for the Care and Use of Laboratory Animals of the National Institutes of Health. 


\section{Competing interests}

The authors declare that they have no competing interests.

\begin{abstract}
Author details
${ }^{1}$ Rocky Mountain Laboratories, Laboratory of Persistent Viral Diseases, National Institute of Allergy \& Infectious Diseases, National Institutes of Health, 903 S. 4th Str, Hamilton, MT 59840, USA. ${ }^{2}$ Rocky Mountain Laboratories, Laboratory of Virology, National Institute of Allergy \& Infectious Diseases, National Institutes of Health, Hamilton, MT, USA. ${ }^{3}$ National CJD Research \& Surveillance Unit, Centre for Clinical Brain Sciences, School of Clinical Sciences, University of Edinburgh, Edinburgh, UK. ${ }^{4}$ Department of Neurosciences, Biomedicine, and Movement Sciences, University of Verona, Verona, Italy.
\end{abstract}

\section{Received: 28 May 2020 Accepted: 29 May 2020}

\section{Published online: 09 June 2020}

\section{References}

1. Asante EA, Gowland I, Grimshaw A, Linehan JM, Smidak M, Houghton R, Osiguwa O, Tomlinson A, Joiner S, Brandner S et al (2009) Absence of spontaneous disease and comparative prion susceptibility of transgenic mice expressing mutant human prion proteins. J Gen Virol 90:546-558. https://doi.org/10.1099/vir.0.007930-0

2. Asante EA, Linehan JM, Desbruslais $M$, Joiner S, Gowland I, Wood AL, Welch J, Hill AF, Lloyd SE, Wadsworth JD et al (2002) BSE prions propagate as either variant CJD-like or sporadic CJD-like prion strains in transgenic mice expressing human prion protein. EMBO J 21:6358-6366. https://doi.org/10. 1093/emboj/cdf653

3. Baiardi S, Rossi M, Capellari S, Parchi P (2019) Recent advances in the histomolecular pathology of human prion disease. Brain Pathol 29:278-300. https://doi.org/10.1111/bpa.12695

4. Bessen RA, Marsh RF (1992) Identification of two biologically distinct strains of transmissible mink encephalopathy in hamsters. J Gen Virol 73(Pt 2):329_ 334. https://doi.org/10.1099/0022-1317-73-2-329

5. Bishop MT, Will RG, Manson JC (2010) Defining sporadic Creutzfeldt-Jakob disease strains and their transmission properties. Proc Natl Acad Sci U S A 107:12005-12010. https://doi.org/10.1073/pnas.1004688107

6. Brandel JP, Preece M, Brown P, Croes E, Laplanche JL, Agid Y, Will R, Alperovitch A (2003) Distribution of codon 129 genotype in human growth hormone-treated CJD patients in France and the UK. Lancet 362:128-130. https://doi.org/10.1016/s0140-6736(03)13867-6

7. Brown P, Brandel JP, Sato T, Nakamura Y, MacKenzie J, Will RG, Ladogana A, Pocchiari M, Leschek EW, Schonberger LB (2012) latrogenic CreutzfeldtJakob disease, final assessment. Emerg Infect Dis 18:901-907. https://doi. org/10.3201/eid1806.120116

8. Brown P, Gibbs CJ Jr, Rodgers-Johnson P, Asher DM, Sulima MP, Bacote A Goldfarb LG, Gajdusek DC (1994) Human spongiform encephalopathy: the National Institutes of Health series of 300 cases of experimentally transmitted disease. Ann Neurol 35:513-529. https://doi.org/10.1002/ana. 410350504

9. Bruce ME, Will RG, Ironside JW, McConnell I, Drummond D, Suttie A, McCardle L, Chree A, Hope J, Birkett C et al (1997) Transmissions to mice indicate that 'new variant' CJD is caused by the BSE agent. Nature 389:498501. https://doi.org/10.1038/39057

10. Cali I, Castellani R, Alshekhlee A, Cohen Y, Blevins J, Yuan J, Langeveld JP, Parchi P, Safar JG, Zou WQ et al (2009) Co-existence of scrapie prion protein types 1 and 2 in sporadic Creutzfeldt-Jakob disease: its effect on the phenotype and prion-type characteristics. Brain 132:2643-2658. https://doi. org/10.1093/brain/awp196

11. Cervenakova L, Goldfarb LG, Garruto R, Lee HS, Gajdusek DC, Brown P (1998) Phenotype-genotype studies in kuru: implications for new variant Creutzfeldt-Jakob disease. Proc Natl Acad Sci U S A 95:13239-13241. https:// doi.org/10.1073/pnas.95.22.13239

12. Collinge J, Palmer MS, Dryden AJ (1991) Genetic predisposition to iatrogenic Creutzfeldt-Jakob disease. Lancet 337:1441-1442. https://doi.org/10.1016/ 0140-6736(91)93128-v

13. Collinge J, Sidle KC, Meads J, Ironside J, Hill AF (1996) Molecular analysis of prion strain variation and the aetiology of 'new variant' CJD. Nature 383: 685-690. https://doi.org/10.1038/383685a0

14. de Silva R, Ironside JW, McCardle L, Esmonde T, Bell J, Will R, Windl O, Dempster M, Estibeiro P, Lathe R (1994) Neuropathological phenotype and 'prion protein' genotype correlation in sporadic Creutzfeldt-Jakob disease. Neurosci Lett 179:50-52. https://doi.org/10.1016/0304-3940(94)90932-6

15. Dickinson AG (1976) Scrapie in sheep and goats. Front Biol 44:209-241

16. Doh-ura K, Kitamoto T, Sakaki Y, Tateishi J (1991) CJD discrepancy. Nature 353:801-802. https://doi.org/10.1038/353801b0

17. Dougherty RM (1964) Animal virus titration techniques. In: Harris RJC (ed) Techniques in Experimental Virology. Academic, City, pp 169-223

18. Gill AC, Castle AR (2018) The cellular and pathologic prion protein. Handb Clin Neurol 153:21-44. https://doi.org/10.1016/b978-0-444-63945-5.00002-7

19. Head MW, Bunn TJ, Bishop MT, McLoughlin V, Lowrie S, McKimmie CS, Williams MC, McCardle L, MacKenzie J, Knight R et al (2004) Prion protein heterogeneity in sporadic but not variant Creutzfeldt-Jakob disease: UK cases 1991-2002. Ann Neurol 55:851-859. https://doi.org/10.1002/ana.20127

20. Hill AF, Desbruslais M, Joiner S, Sidle KC, Gowland I, Collinge J, Doey L, Lantos P (1997) The same prion strain causes VCJD and BSE. Nature 389(448-450):526. https://doi.org/10.1038/38925

21. Kitamoto T, Doh-ura K, Muramoto T, Miyazono M, Tateishi J (1992) The primary structure of the prion protein influences the distribution of abnormal prion protein in the central nervous system. Am J Pathol 141: $271-277$

22. Knight R (2017) Infectious and sporadic prion diseases. Prog Mol Biol Transl Sci 150:293-318. https://doi.org/10.1016/bs.pmbts.2017.06.010

23. Kobayashi A, Iwasaki Y, Otsuka H, Yamada M, Yoshida M, Matsuura Y, Mohri S, Kitamoto T (2013) Deciphering the pathogenesis of sporadic CreutzfeldtJakob disease with codon $129 \mathrm{MN}$ and type 2 abnormal prion protein. Acta Neuropathol Commun 1:74. https://doi.org/10.1186/2051-5960-1-74

24. Kobayashi A, Mizukoshi K, Iwasaki Y, Miyata H, Yoshida Y, Kitamoto T (2011) Co-occurrence of types 1 and $2 \operatorname{PrP}$ (res) in sporadic Creutzfeldt-Jakob disease MM1. Am J Pathol 178:1309-1315. https://doi.org/10.1016/j.ajpath. 2010.11.069

25. Kobayashi A, Teruya K, Matsuura Y, Shirai T, Nakamura Y, Yamada M, Mizusawa H, Mohri S, Kitamoto T (2015) The influence of PRNP polymorphisms on human prion disease susceptibility: an update. Acta Neuropathol 130:159-170. https://doi.org/10.1007/s00401-015-1447-7

26. Ladogana A, Kovacs GG (2018) Genetic Creutzfeldt-Jakob disease. Handb Clin Neurol 153:219-242. https://doi.org/10.1016/b978-0-444-63945-5.00013-1

27. Miyazono M, Kitamoto T, Doh-ura K, Iwaki T, Tateishi J (1992) CreutzfeldtJakob disease with codon 129 polymorphism (valine): a comparative study of patients with codon 102 point mutation or without mutations. Acta Neuropathol 84:349-354. https://doi.org/10.1007/BF00227660

28. Moore RA, Head MW, Ironside JW, Ritchie DL, Zanusso G, Choi YP, Priola SA (2016) The distribution of prion protein Allotypes differs between sporadic and iatrogenic Creutzfeldt-Jakob disease patients. PLoS Pathog 12:e1005416. https://doi.org/10.1371/journal.ppat.1005416

29. Orru CD, Hughson AG, Groveman BR, Campbell KJ, Anson KJ, Manca M, Kraus A, Caughey B (2016) Factors that improve RT-QulC detection of prion seeding activity. Viruses 8. https://doi.org/10.3390/v8050140

30. Parchi P, Castellani R, Capellari S, Ghetti B, Young K, Chen SG, Farlow M, Dickson DW, Sima AA, Trojanowski JQ et al (1996) Molecular basis of phenotypic variability in sporadic Creutzfeldt-Jakob disease. Ann Neurol 39: 767-778. https://doi.org/10.1002/ana.410390613

31. Parchi P, Giese A, Capellari S, Brown P, Schulz-Schaeffer W, Windl O, Zerr I, Budka H, Kopp N, Piccardo P et al (1999) Classification of sporadic Creutzfeldt-Jakob disease based on molecular and phenotypic analysis of 300 subjects. Ann Neurol 46:224-233. https://doi.org/10.1002/15318249(199908)46:2\%3C224::AID-ANA12\%3E3.0.CO;2-W

32. Parchi $P$, Notari $S$, Weber $P$, Schimmel H, Budka H, Ferrer I, Haik S, Hauw JJ, Head MW, Ironside JW et al (2009) Inter-laboratory assessment of PrPSC typing in creutzfeldt-jakob disease: a Western blot study within the NeuroPrion consortium. Brain Pathol 19:384-391. https://doi.org/10.1111/j. 1750-3639.2008.00187.x

33. Parchi P, Strammiello R, Giese A, Kretzschmar H (2011) Phenotypic variability of sporadic human prion disease and its molecular basis: past, present, and future. Acta Neuropathol 121:91-112. https://doi.org/10.1007/s00401-0100779-6

34. Parchi P, Strammiello R, Notari S, Giese A, Langeveld JP, Ladogana A, Zerr I, Roncaroli F, Cras P, Ghetti B et al (2009) Incidence and spectrum of sporadic Creutzfeldt-Jakob disease variants with mixed phenotype and cooccurrence of PrPSc types: an updated classification. Acta Neuropathol 118: 659-671. https://doi.org/10.1007/s00401-009-0585-1 
35. Priola SA, Ward AE, McCall SA, Trifilo M, Choi YP, Solforosi L, Williamson RA, Cruite JT, Oldstone MB (2013) Lack of prion infectivity in fixed heart tissue from patients with Creutzfeldt-Jakob disease or amyloid heart disease. J Virol 87:9501-9510. https://doi.org/10.1128/jvi.00692-13

36. Puoti G, Giaccone G, Rossi G, Canciani B, Bugiani O, Tagliavini F (1999) Sporadic Creutzfeldt-Jakob disease: co-occurrence of different types of PrP (Sc) in the same brain. Neurology 53:2173-2176. https://doi.org/10.1212/wnl. 53.9.2173

37. Race B, Meade-White KD, Miller MW, Barbian KD, Rubenstein R, LaFauci G, Cervenakova L, Favara C, Gardner D, Long D et al (2009) Susceptibilities of nonhuman primates to chronic wasting disease. Emerg Infect Dis 15:13661376. https://doi.org/10.3201/eid1509.090253

38. Race B, Williams K, Chesebro B (2019) Transmission studies of chronic wasting disease to transgenic mice overexpressing human prion protein using the RTQulC assay. Vet Res 50:6. https://doi.org/10.1186/s13567-019-0626-2

39. Ritchie DL, Barria MA, Peden AH, Yull HM, Kirkpatrick J, Adlard P, Ironside JW, Head MW (2017) UK iatrogenic Creutzfeldt-Jakob disease: investigating human prion transmission across genotypic barriers using human tissuebased and molecular approaches. Acta Neuropathol 133:579-595. https:// doi.org/10.1007/s00401-016-1638-x

40. Rudge P, Jaunmuktane Z, Adlard P, Bjurstrom N, Caine D, Lowe J, Norsworthy P, Hummerich H, Druyeh R, Wadsworth JD et al (2015) latrogenic CJD due to pituitary-derived growth hormone with genetically determined incubation times of up to 40 years. Brain 138:3386-3399. https://doi.org/10.1093/brain/awv235

41. Schoch G, Seeger H, Bogousslavsky J, Tolnay M, Janzer RC, Aguzzi A, Glatzel M (2006) Analysis of prion strains by PrPSc profiling in sporadic Creutzfeldt-Jakob disease. PLoS Med 3:e14. https://doi.org/10.1371/journal.pmed.0030014

42. Schulz-Schaeffer WJ, Giese A, Windl O, Kretzschmar HA (1996) Polymorphism at codon 129 of the prion protein gene determines cerebellar pathology in Creutzfeldt-Jakob disease. Clin Neuropathol 15:353-357

43. Telling GC, Scott M, Hsiao KK, Foster D, Yang SL, Torchia M, Sidle KC, Collinge J, DeArmond SJ, Prusiner SB (1994) Transmission of CreutzfeldtJakob disease from humans to transgenic mice expressing chimeric humanmouse prion protein. Proc Natl Acad Sci U S A 91:9936-9940. https://doi. org/10.1073/pnas.91.21.9936

44. Wadsworth JD, Joiner S, Linehan JM, Desbruslais M, Fox K, Cooper S, Cronier S, Asante EA, Mead S, Brandner S et al (2008) Kuru prions and sporadic Creutzfeldt-Jakob disease prions have equivalent transmission properties in transgenic and wild-type mice. Proc Natl Acad Sci U S A 105:3885-3890. https://doi.org/10.1073/pnas.0800190105

45. Wilham JM, Orru CD, Bessen RA, Atarashi R, Sano K, Race B, Meade-White KD, Taubner LM, Timmes A, Caughey B (2010) Rapid end-point quantitation of prion seeding activity with sensitivity comparable to bioassays. PLoS Pathog 6:e1001217. https://doi.org/10.1371/journal.ppat.1001217

\section{Publisher's Note}

Springer Nature remains neutral with regard to jurisdictional claims in published maps and institutional affiliations.

Ready to submit your research? Choose BMC and benefit from:

- fast, convenient online submission

- thorough peer review by experienced researchers in your field

- rapid publication on acceptance

- support for research data, including large and complex data types

- gold Open Access which fosters wider collaboration and increased citations

- maximum visibility for your research: over $100 \mathrm{M}$ website views per year

At BMC, research is always in progress.

Learn more biomedcentral.com/submissions 